\title{
Sociality genes are associated with human-directed social behaviour in golden and Labrador retriever dogs
}

\author{
Mia E Persson ${ }^{\text {Corresp.. }}{ }^{1}$, Ann-Sofie Sundman ${ }^{1}$, Lise-Lotte Halldén ${ }^{1}$, Agaia J Trottier ${ }^{1}$, Per Jensen ${ }^{\text {Corresp. } 1}$ \\ ${ }^{1}$ AVIAN Behaviour Genomics and Physiology Group, IFM Biology, Linköping University, Linköping, Sweden \\ Corresponding Authors: Mia E Persson, Per Jensen \\ Email address: mia.persson@liu.se, per.jensen@liu.se
}

Background. Dogs have human-directed social skills that allow them to communicate and cooperate with humans. We have previously identified two loci on chromosome 26 associated with human contactseeking behaviours during an unsolvable problem task in laboratory beagles (Persson et al., 2016). The aim of the present study was to verify the SNPs in additional dog breeds and investigate possible associations to other social skills. We also studied how the allele frequencies have changed during domestication and recent selection.

Methods. Dogs of two breeds, 61 golden retrievers and 100 Labrador retrievers, were phenotyped and genotyped, and 19 wolves were genotyped. The Labrador retrievers were divided into common and field type by pedigree data to make it possible to study the effects of recent selection. All dogs were tested in an unsolvable problem task where human-directed social behaviours were scored. DNA from dogs (buccal swabs) and wolves (blood or brain tissue) was analysed for genotype on two of the previously identified SNP markers, BICF2G630798942 (SNP1) and BICF2S23712114 (SNP2), by pyrosequencing.

Results. There was genetic variation for SNP1 in both dog breeds whereas the wolves were fixed for this polymorphism, and for SNP2 there was variation in both dogs and wolves. For both SNPs, Labrador retriever types differed significantly in allele frequencies. We found associations between SNPs and human-directed social behaviour in both dog breeds. In golden retrievers, SNP1 was associated with physical contact variables, for example with the duration of physical contact with the owner $\left(\mathrm{F}_{2,56}=\right.$ 4.389, $p=0.017)$. SNP2 was associated with several behavioural variables in both breeds, among others owner gazing frequency in both golden retrievers $\left(F_{2,55}=6.330, p=0.003\right)$ and Labradors $\left(F_{1,93}=5.209, p\right.$ $=0.025$ ).

Discussion. Our results verify the association between the previously identified SNPs and humandirected social behaviour scored in an unsolvable problem task. Differences in allele frequencies suggest that these loci have been affected by selection. The results suggest that these genomic regions are involved in human-directed social behaviour in not only beagles but in other dog breeds as well. We hypothesise that they may have been important during dog domestication. 


\section{Sociality genes are associated with human-directed social}

\section{2 behaviour in golden and Labrador retriever dogs}

3

4 Mia E. Persson ${ }^{1}$, Ann-Sofie Sundman ${ }^{1}$, Lise-Lotte Halldén, Agaia J. Trottier, Per Jensen

5

6 AVIAN Behaviour Genomics and Physiology Group, IFM Biology, Linköping University,

758183 Linköping, Sweden

8

$9{ }^{1}$ These authors contributed equally to this work.

10

11 Corresponding author:

12 Per Jensen

13

14 Email address: per.jensen@liu.se

15

16

17

18

19 


\section{ABSTRACT}

21 Background. Dogs have human-directed social skills that allow them to communicate and

22 cooperate with humans. We have previously identified two loci on chromosome 26 associated

23 with human contact-seeking behaviours during an unsolvable problem task in laboratory beagles

24 (Persson et al., 2016). The aim of the present study was to verify the SNPs in additional dog

25 breeds and investigate possible associations to other social skills. We also studied how the allele

26 frequencies have changed during domestication and recent selection.

27 Methods. Dogs of two breeds, 61 golden retrievers and 100 Labrador retrievers, were

28 phenotyped and genotyped, and 19 wolves were genotyped. The Labrador retrievers were

29 divided into common and field type by pedigree data to make it possible to study the effects of

30 recent selection. All dogs were tested in an unsolvable problem task where human-directed social

31 behaviours were scored. DNA from dogs (buccal swabs) and wolves (blood or brain tissue) was

32 analysed for genotype on two of the previously identified SNP markers, BICF2G630798942

33 (SNP1) and BICF2S23712114 (SNP2), by pyrosequencing.

34 Results. There was genetic variation for SNP1 in both dog breeds whereas the wolves were fixed

35 for this polymorphism, and for SNP2 there was variation in both dogs and wolves. For both

36 SNPs, Labrador retriever types differed significantly in allele frequencies. We found associations

37 between SNPs and human-directed social behaviour in both dog breeds. In golden retrievers,

38 SNP1 was associated with physical contact variables, for example with the duration of physical

39 contact with the owner $\left(\mathrm{F}_{2,56}=4.389, \mathrm{p}=0.017\right)$. SNP2 was associated with several behavioural

40 variables in both breeds, among others owner gazing frequency in both golden retrievers $\left(\mathrm{F}_{2,55}=\right.$

$416.330, \mathrm{p}=0.003)$ and Labradors $\left(\mathrm{F}_{1,93}=5.209, \mathrm{p}=0.025\right)$. 
42 Discussion. Our results verify the association between the previously identified SNPs and

43 human-directed social behaviour scored in an unsolvable problem task. Differences in allele

44 frequencies suggest that these loci have been affected by selection. The results suggest that these 45 genomic regions are involved in human-directed social behaviour in not only beagles but in other 46 dog breeds as well. We hypothesise that they may have been important during dog 47 domestication.

\section{INTRODUCTION}

50 Social behaviours are complex traits affected by environmental factors as well as by many genes,

51 each with small effects. The genetics of complex traits such as social behaviour is difficult to

52 study in humans as it requires a standardized environment, dense genotyping as well as

53 phenotyping of a large number of individuals. The dog (Canis familiaris) on the other hand, has

54 a genome with large haplotype blocks and is thus more convenient for genetic mapping

55 (Lindblad-Toh et al. 2005). In addition, their human-like social skills could make them a suitable

56 model species for human social behaviour and disorders.

57

58 Through sharing our ecological niche for thousands of years, dogs have developed social talents

59 that, in some cases, have been reported to surpass the skills of our closest relative, the

60 chimpanzee (Pan troglodytes), as well as their own wolf ancestor (Canis lupus) (Hare \&

61 Tomasello 1999; Hare \& Tomasello 2005). For example, dogs are able to comprehend human

62 ostensive cues and referential gestures such as pointing and gazing (Lakatos et al. 2012; Soproni

63 et al. 2001). They are also able to communicate with humans through intentional communicative

64 referential gestures involving both attention-seeking and directional-showing behaviour 
65 (Marshall-Pescini et al. 2013; Miklosi et al. 2000; Passalacqua et al. 2011). Furthermore, dogs

66 have been demonstrated to discriminate between human emotions when viewing facial

67 expressions (Muller et al. 2015). Not even socialised wolves are as prone as dogs to seek human

68 attention (Gacsi et al. 2009; Topal et al. 2005), or to communicate with humans through mutual

69 gazing (Nagasawa et al. 2015). Different hypotheses for how these differences between the wolf

70 and the dog evolved has been proposed. For example, Hare and Tomasello (2005) suggested that

71 selection against fear and aggression towards humans also mediated the evolution of dogs' social

72 skills. More recently, however, Range and Viranyi (2015) showed that wolves are as attentive to

73 both human and conspecific actions as dogs are. They propose the canine cooperation

74 hypothesis, suggesting that wolf-wolf cooperation established the basis for the evolution of dog-

75 human cooperation.

76

77 Human-directed contact-seeking behaviours have specifically been studied using a problem-

78 solving paradigm. Hare and Tomasello (2005) and Miklósi et al. (2003) showed that dogs and

79 socialised wolves differ in their human-directed contact-seeking behaviour when faced with an

80 unsolvable task. Whereas wolves were more oriented towards the task, dogs quickly gave up and

81 turned to a nearby human in a help-seeking manner. Hence, behavioural tests involving

82 unsolvable tasks that stimulate communication and attention-seeking towards humans can be

83 used to study dog-human social interactions, including variation between and within breeds

84 (Persson et al. 2015; Persson et al. 2017; Sundman et al. 2018).

85

86 When studying dogs' human-directed social behaviour it is important to take into account that

87 dogs form strong attachment bonds with their owners (Topal et al. 1998). It has been suggested 
88 that owners function as a secure base influencing persistence in cognitive tasks (Horn et al.

89 2013), because the presence of the owner affects dogs' duration of task manipulation.

90 Additionally, these authors found that dogs spend more time in proximity of their owner and the

91 presence or absence of the owner affected dogs' interactions towards the unfamiliar

92 experimenter. It is therefore relevant to analyse social interactions towards an unfamiliar

93 experimenter and the familiar owner separately if both are present during a cognitive task.

94 Consistent with this, we previously found that dogs' social behaviours directed at owners and

95 those directed at unfamiliar experimenter were separated into different components in a principal 96 component analysis (Sundman et al. 2018).

98 The dog is not only well-suited for studies on social behaviour, the species is also well-suited for 99 studies of the genetics of both simple and complex traits such as social behaviours. The structure 100 of the dog genome with long regions of linkage disequilibrium is particularly suitable for 101 genome-wide studies identifying candidate regions for traits of interest (Lindblad-Toh et al.

102 2005; Sutter et al. 2004). Regarding human-directed social behaviour, heritability estimates show 103 a significant genetic component underlying variation in behaviours as measured in an unsolvable 104 problem task (Persson et al. 2015). Furthermore, genome-wide association studies (GWAS) have 105 identified two candidate regions on chromosome 26 associated with human-directed social 106 behaviour in laboratory beagles, with single nucleotide polymorphisms (SNPs) located within the 107 SEZ6L and $A R V C F$ genes (Persson et al. 2016). Interestingly, these genes have previously been 108 associated with human social disorders such as autism for SEZ6L (Chapman et al. 2015) and 109 schizophrenia for $A R V C F$ (Sim et al. 2012). Additionally, Persson et al. (2016) found that the 110 SNP associated with the gene $A R V C F$ is in linkage with three other genes of interest for dogs' 
111 sociability, e.g., the COMT gene that has previously been associated with mood regulation in

112 humans (Qayyum et al. 2015).

113

114 These earlier findings suggest a possible cross-species genetic basis for social behaviour shared

115 between dogs and humans. However, further studies are necessary to verify that the same SNP

116 markers are associated with human-directed contact seeking in other dog breeds. In the present

117 study, we utilised behavioural data collected in two different experiments in two other breeds,

118 each experiment using similar methods for studying dog-human interactions in a standardised

119 behavioural test. In both breeds we collected DNA and analysed associations with the previously

120 reported candidate SNPs. The aim of the study was thus to investigate whether there are

121 associations between human-directed social behaviour, as measured in an unsolvable problem

122 task, and two candidate SNP markers in groups of golden and Labrador retrievers. It is possible

123 that genetic variants affecting social behaviour have been under selection during domestication

124 and more recent breed formations. To provide some tentative data in relation to this, we

125 genotyped wolves and included a dog breed that has undergone recent selection for its

126 cooperative bond with humans, the Labrador retriever. The Labrador retriever has recently been

127 split into a common and a hunting type differing in many aspects of social behaviour (Sundman

128 et al. 2016).

129

130 MATERIALS AND METHODS

131 Ethical note

132 These studies were carried out in accordance with the relevant guidelines and the ethical permit 133 approved by the regional ethical committee for animal experiments in Linköping, Sweden 
134 (permit number: 51-13). All owners had given their informed consent for their dogs'

135 participation. Wolf samples were donated by the veterinarians at Kolmården Wildlife Park and

136 Borås Animal Park in Sweden. All wolf samples were collected in connection with veterinary

137 motivated procedures and no particular ethical licence was therefore required for them.

138

\section{Subjects}

140 Dogs of the breeds golden and Labrador retrievers were recruited to participate by finding dog

141 owners through social media, local radio and advertisements. In total, 61 golden retrievers (34

142 females and 27 males) and 100 Labrador retrievers (52 females and 48 males) were tested in the

143 same unsolvable problem task and additionally genotyped for the two candidate SNPs. All dogs

144 were originally recruited for and used in other studies. Golden retrievers participated in a study

145 involving intranasal oxytocin treatment and its effect on behaviours in an unsolvable problem

146 task (Persson et al. 2017) and, due to this, they were required to be at least 4 months of age

147 (mean age $5 \pm$ SE 0.5 years; range 4 months-12 years) and not pregnant or lactating. Labrador

148 retrievers participated in a study on correlations between the unsolvable problem task and other

149 behaviour assessments (Sundman et al. 2018) and were required to be at least 1 and not older

150 than 4 years of age (mean age $2.43 \pm 0.195$ ). Participating dogs also had to be registered as

151 purebred by the Swedish Kennel Club.

152

153 In addition, the same candidate SNPs were genotyped in 21 Scandinavian wolf samples (Canis

154 lupus lupus, 7 females and 14 males) (Table S1). Out of these, eighteen blood samples were

155 donated by Kolmården Wildlife Park, Sweden. These blood samples were old samples collected

156 between 2008-2016 upon routine procedures for veterinarian purposes. The wolves at Kolmården 
157 Wildlife Park were originally born in captivity and originated from 5 different animal parks in

158 Scandinavia. Three brain samples, collected after death from reasons unrelated to any scientific

159 studies, were donated by Borås Animal Park, Sweden. One of the latter three was wild-caught

160 and the others born in captivity at the zoo. For more information on the wolf samples, see Table $161 \mathrm{~S} 1$.

162

163 By use of pedigree information, Labrador retrievers were divided into two types: common and

164 field. If ancestors for at least three generations back were bred for field work, which can be seen 165 in titles of ancestors e.g., field-trial champion, the dogs were classified as field-type Labrador 166 retrievers. If ancestors instead had show titles, they were classified as common-type Labrador 167 retrievers. Labrador retrievers with mixed ancestry were not included in the study. We used the 168 Swedish Kennel Club's online registry (Hunddata, http://hundar.skk.se/hunddata/) and 169 k9data.com (http://www.k9data.com/) for pedigrees. Based on the pedigree analysis we 170 classified 52 Labrador retrievers as common (28 females and 24 males) and 48 as field type (24

171 females and 24 males). For golden retrievers, we did not have sufficient information to perform a 172 similar division, and they were therefore all treated as one single breed.

173

174 Procedure

175 Upon arrival at the testing site, owners were informed of the testing procedure. Buccal DNA 176 samples were collected either prior to the testing (golden retrievers) or after the testing (Labrador 177 retrievers). To assure sufficient food motivation in the dogs, their willingness to eat the treats 178 used in the unsolvable problem task was confirmed as described in Persson et al. (2015). Briefly, 179 dogs were presented with three quarter-pieces of Frolic $($ C on a plastic plate of the same material 
180 as the problem-solving device but without a lid. The treats were presented one at the time. When

181 the dog ate a treat, another was placed until the dog had consumed the three treats. All subjects

182 consumed all pieces within 20 seconds and were therefore not considered to differ in their

183 willingness to eat the treats.

184

185 Two female experimenters tested the dogs, one person tested the golden retrievers and one the 186 Labrador retrievers. The video analyses were performed by the two experimenters.

188 Subjects of the breed golden retriever were part of a parallel study investigating effects of 189 oxytocin treatment on dogs' human directed social behaviour (Persson et al. 2017). Therefore, as part of this parallel study, subsequently to DNA sampling half of the females and half of the males received an intranasal dose of 20 IU oxytocin 45 minutes prior to the behavioural test.

192 Individuals that were not given an oxytocin treatment were instead given saline as a control 193 treatment. After the food motivation test, these dogs were taken for a 30-minute walk followed 194 by 10 minutes of resting in the car immediately prior to the behaviour test. Treatment was taken 195 into account in the later analyses, as described below. The experimenter who tested the golden 196 retrievers was blinded to which hormone treatment the dogs received until after the behavioural 197 video analysis. Subjects of the breed Labrador retriever had been subjected to a standardized test 198 battery (Behaviour and Personality test for Dogs, Swedish Kennel Club) before testing them in 199 the unsolvable problem task. Lastly, they were tested in a pointing test.

\section{Unsolvable problem task}


202 Testing was carried out at ten different locations in Sweden during the autumn of 2014 (Labrador 203 retrievers) and autumn of 2015 (golden retrievers). Results from the behaviour test have been 204 previously published in Sundman et al. (2018) (Labrador retrievers) and in Persson et al. (2017) 205 (golden retrievers). The unsolvable problem task was performed in the same way in both breeds. 206 To have a uniform setting, testing took place in a $3 \times 3$ m marquee tent without the presence of 207 any other dogs. The tent had three walls and no flooring. A mesh fence was placed at the open 208 side to keep the dogs within the tent (testing area). An HD camcorder (Canon Legria HF G25) 209 was placed on a camera stand approximately 3 meters from the testing area to record the 210 behaviour of each dog.

211

212 Dogs were tested with the unsolvable problem task thoroughly described in Persson et al. (2015) 213 with the addition of the presence of the owner. The device used consists of a plastic tray ( $55 \times 25$ $214 \mathrm{~cm}$ ) with three identical circular wells $(7 \mathrm{~cm}$ in diameters) covered with plexiglass lids with 215 odour ports (Fig. 1). Three quarter-pieces of Frolic $(\mathcal{C}$ dog treats were placed underneath each lid.

216 The dogs could easily access the treats in two of the three wells by sliding the lids to the side.

217 However, the lid in the middle could not be opened hence making the task unsolvable. The

218 experimenter cleaned, prepared and placed the unsolvable problem task on the ground 219 approximately $15-30 \mathrm{~cm}$ from the middle of the back wall prior to the arrival of each dog.

220

221 Upon arrival at the testing arena, owners were reminded to stand passively immediately close to 222 the fence at the front right corner inside the tent, facing the problem task. The experimenter was 223 standing in the same position but on the opposite side of the tent (in the front left corner). After 224 closing the fence gate, the owner was asked to unleash the dog that then could freely move 
225 around inside the testing area from this point onwards. The owner had been instructed to not

226 interact with the dog unless it was attempting to escape. If the dog tried to leave the tent, the

227 owner was allowed to interrupt and call the dog back. Behaviours were not recorded during this

228 interruption. If the dog had not opened any of the lids within 60 seconds, the experimenter

229 opened both solvable lids halfway and immediately went back to her original position. The

230 duration of the behaviour test was three minutes.

231

232 The behaviours scored from the behaviour test were the human-directed social behaviours

233 proximity, physical contact and gazing in relation to owner and experimenter. Duration and

234 frequency were scored for each of these behaviours as described in the ethogram (Table 1). In

235 addition to the social behaviours, we scored the duration of the time the dog spent in close

236 proximity of the test-setup. The behaviours were scored from the video recordings using the

237 Observer XT 10, Noldus software.

238

239 DNA sampling, extraction and genotyping

240 Buccal cells were collected from the dogs by rubbing a cotton swab on the inside of their cheek

241 for approximately 20 seconds. Buccal samples were stored at $4{ }^{\circ} \mathrm{C}$ and wolf samples (blood and

242 serum) were stored at $-20{ }^{\circ} \mathrm{C}$ until DNA extraction. The standard protocol of the Isohelix DDK-

24350 kit was used to extract DNA from buccal swabs, with the exception that samples were kept in

244 Lysis Buffer and proteinase K for 48 hours prior to continuing with the protocol. Single $50 \mu 1$

245 elusions were used. DNA was also extracted from fifteen whole blood and three serum wolf

246 samples using the QIAGEN DNeasy® Blood and Tissue Kit and from three wolf brain samples

247 using QIAGEN AllPrep DNA/RNA/miRNA Universal Kit, both by standard protocol. 
248 Subsequently, DNA yield was quantified using a Nanodrop ND-1000 and all isolated samples

249 were stored at $-20{ }^{\circ} \mathrm{C}$ until further use.

250

251 Genotyping was performed on the two SNPs identified in Persson et al. (2016),

252

BICF2G630798942 (rs23313128, chr26:20025266C/A) and BICF2S23712114 (rs23317526,

253

254

255

256

257

258

259

260

261

262

263

264

265

266

267

268

269

270

chr26:29319675A/G). Hereafter, BICF2G630798942 will be referred to as SNP1 and

BICF2S23712114 as SNP2. Polymerase chain reaction (PCR) and subsequent pyrosequencing

were used to genotype both wolf and dog samples for the two SNPs. Primers were designed using the PyroMark Assay Design software by QIAGENC. The primers used for SNP1 were:

forward biotinylated in 5' CTGCCAGGGACTCCTGAG, reverse

CTCAAGGCAGCCCATCACT and sequencing reverse GGAGGCTTGCTGCCG. For SNP2 the primers used were: forward biotinylated in 5' CATGTCACAGTTGAGGGGATAGGT, reverse TCTTCAGACAGCCCACCCA and sequencing reverse CAGTCCAGGAAGGAATA. For each sample, the PCR-mixture contained $0.12 \mu$ DreamTaq $^{\mathrm{TM}}$ DNA Polymerase $5 \mathrm{u} / \mu \mathrm{l}$ (Thermo Scientific), 2,5 $\mu$ l of 10X DreamTaq ${ }^{\mathrm{TM}}$ Buffer (Thermo Scientific), $0.5 \mu 1 \mathrm{dNTP} 10 \mathrm{mM}(2.5 \mathrm{mM}$ each, BIOLINE), $0.5 \mu 1$ of each primer diluted to $5 \mu \mathrm{M}$ (Invitrogen), $19.9 \mu 1$ of nuclease free water and approximately 100-200 ng of DNA template. The final PCR volume was $25 \mu \mathrm{l}$ for each sample and the reaction was run on the Palmcycler PCR by Corbett. The PCR cycle consisted of an initial denaturation at $95^{\circ} \mathrm{C}$ for $3 \mathrm{~min}, 40$ cycles of $30 \mathrm{~s}$ denaturation at $95^{\circ} \mathrm{C}, 30 \mathrm{~s}$ annealing at $63^{\circ} \mathrm{C}$ for the SNP1 primers and $61^{\circ} \mathrm{C}$ for SNP2 primers, $30 \mathrm{~s}$ extension at $72^{\circ} \mathrm{C}$ and a 10 min final extension at $72^{\circ} \mathrm{C}$. Pyrosequencing was performed on the entire PCR product according to the PyroMark Q24 Vacuum Workstation Quick-Start Guide found at www.qiagen.com. The results were analysed using the PyroMark Q24 2.0.6 software. 
271

272 Genotyping of the SNP1 marker was successful in all 61 golden retriever samples, in 97

273 Labrador retriever samples (genotyping failed in one male and two female samples) and in 19

274 wolf samples (two female samples failed). SNP2 was successfully genotyped in 60 golden

275 retrievers (one female sample failed), in 98 Labrador retrievers (two female samples failed) and

276 in 19 wolves (two female samples failed).

277

278 Statistical analysis

279 Except for Hardy-Weinberg Estimates (HWE), all statistical analyses wereif carried out using 280 IBM SPSS statistics software version 22 and 25. Behaviour data was checked for normality both

281 visually and with the Kolmogorov-Smirnov test, and, if necessary, transformed using $\log 10$ $282(\mathrm{x}+1)$. To analyse behaviour data, Generalized Linear Mixed Models were used. For golden 283 retriever analyses, statistical models contained oxytocin treatment, sex and SNP genotype and for 284 Labrador retriever analyses, the models contained type, sex and SNP genotype. The two SNPs 285 were tested separately together with the other fixed variables and Bonferroni correction was used 286 to account for multiple testing in post-hoc comparisons. Data distribution was set to normal with 287 a link function or gamma with a log function depending on data distribution. Best model288 distribution fit was determined by Akaike measurements comparisons. Final models for each 289 behaviour including $\mathrm{F}$ and $\mathrm{P}$ statistics can be found in Table 2 for golden retrievers and Table 3 290 for Labrador retrievers. Inter-observer reliability analysis was done for all behaviours in $10 \%$ of 291 the individuals with correlation coefficients ranging from $0.901-0.999$ (Pearson) and $0.803-1$

292 (Spearman) (Table S2). Fisher's exact test was used to compare genotype frequencies. To 293 calculate HWE, the exact test incorporated in the "genetics" R-package was used. 


\section{RESULTS}

296 Variation was found in SNP1 in golden retrievers (HWE: $\mathrm{p}=0.769)$ and in Labrador retrievers

297 (HWE: $\mathrm{p}=0.153$ ) but all wolves were fixed for the $\mathrm{C}$ allele (Fig. 2A). For SNP2, variation was

298 found in both golden retrievers $(\mathrm{HWE}: \mathrm{p}=1)$, in Labrador retrievers $(\mathrm{HWE}: \mathrm{p}=1)$ and in wolves

299 (HWE: p = 1) (Fig. 2B). Additionally, when looking at the two types of Labrador retriever

300 separately, there was a variation in both SNPs for both the common and the field type and the

301 HWE was not significant for any of them (for SNP1 $p=0.580$ and $p=1$ and for SNP2 $p=1$ and

$302 \mathrm{p}=1$ for common and field, respectively) (Fig. 2).

303

304 The Fisher's exact test showed a significant difference in genotype frequencies between the 305 common and field Labrador retrievers for both SNP1 $(\mathrm{p}<0.001)$ and SNP2 (p=0.031) (Fig. 2).

306 For SNP1, AC was the most common genotype in common type Labrador retrievers whereas CC

307 was the most common in the field type. In SNP2, AA was the most frequent genotype for both

308 types, but the proportion between AA and AG differed between the types. In the common type a

309 larger proportion was of the AG genotype than in the field type.

310

311 In the unsolvable problem task, there were no associations between the SNPs and the time spent

312 close to the test-setup. However, we found effects of both SNPs on behavioural variables related

313 to social behaviour in both breeds. The final models for each social behaviour variable as well as

314 F and P statistics for all behaviours can be found in Table 2 and 3. Figures of all genotype-

315 behaviour associations are presented in supplementary Figure S1. In the golden retriever, the

316 genotype of SNP1 was significantly associated with physical contact, both on the frequency with 
317 the experimenter (Fig $\left.3 \mathrm{~A}, \mathrm{~F}_{1,56}=4.339, \mathrm{p}=0.018\right)$ and on frequency $\left(\right.$ Fig $3 \mathrm{~B}, \mathrm{~F}_{2,56}=6.996, \mathrm{p}=$

318 0.002) and duration (Fig $3 C, F_{2,56}=4.389, p=0.017$ ) with the owner. Golden retrievers with the

319 AA genotype had a higher frequency of physical contact with the experimenter than individuals

320 with AC. The AC genotype had instead more frequent physical contact with their owners than

321 both $\mathrm{AA}$ and $\mathrm{CC}$, and genotypes $\mathrm{AA}$ and $\mathrm{AC}$ had contact for a longer duration than individuals

322 with the CC genotype.

323

324 In the Labrador retrievers we found a significant interaction between genotype of SNP1 and

325 breed type for the duration of gazing at owner $\left(\right.$ Fig $\left.4, F_{1,90}=10.394, p=0.002\right)$. In the field type,

326 dogs with CC genotype gazed longer at their owner than those with AC genotype, whereas there

327 were no differences between the genotypes among the common type.

328

329 SNP2 was significantly associated with several human-directed social behaviours in both breeds.

330 In the golden retrievers, AG individuals spent less time in the experimenter zone than AA and

331 GG dogs $\left(\right.$ Fig $\left.5 \mathrm{~A}, \mathrm{~F}_{2,55}=3.304, \mathrm{p}=0.044\right)$ and AA dogs gazed at the experimenter more

332 frequently than $\mathrm{GG}$ dogs $\left(\mathrm{Fig} 5 \mathrm{~B}, \mathrm{~F}_{2,55}=3.243, \mathrm{p}=0.047\right)$. Individuals carrying the AA and AG

333 genotype gazed at their owners more frequently (Fig $\left.5 \mathrm{C}, \mathrm{F}_{2,55}=6.330, \mathrm{p}=0.003\right)$ and with a

334 longer duration (Fig 5D, $\left.\mathrm{F}_{1,55}=4.477, \mathrm{p}=0.016\right)$ than $\mathrm{GG}$ dogs. Also, golden retrievers with the 335 AG genotype had longer duration of physical contact with their owner than those with AA (Fig $\left.3365 \mathrm{E}, \mathrm{F}_{2,55}=14.809, \mathrm{p}<0.001\right)$.

337

338 In the Labrador retrievers, AA individuals at SNP2 spent more time in the experimenter zone 339 (Fig. 6A, $\left.\mathrm{F}_{1,94}=6.252, \mathrm{p}=0.014\right)$ and visited it more frequently (Fig. 6B, $\mathrm{F}_{1,94}=6.860, \mathrm{p}=$ 
340 0.010), as well as spent more time in the owner zone (Fig. $\left.6 \mathrm{C}, \mathrm{F}_{1,94}=5.945, \mathrm{p}=0.017\right)$ and

341 visited it more frequently (Fig. $6 \mathrm{D}, \mathrm{F}_{1,94}=13.846, \mathrm{p}<0.001$ ). AA individuals also gazed more

342 often at their owner (Fig. $6 \mathrm{E}, \mathrm{F}_{1,93}=5.209, \mathrm{p}=0.025$ ) whereas $\mathrm{AG}$ individuals instead gazed at

343 their owner for a longer duration (Fig. $6 \mathrm{~F}, \mathrm{~F}_{1,93}=7.209, \mathrm{p}=0.009$ ). For the duration of gazing

344 towards experimenter (Fig 7A) and the frequency of gazing towards the owner (Fig 7B) there

345 was an interaction between genotype and type in the Labrador retrievers $\left(F_{1,93}=7.796, p=0.006\right.$

346 and $F_{1,93}=3.947, p=0.05$, respectively). In the field type, AA individuals gazed longer at the

347 experimenter and more often at their owner than AG individuals whereas there were no

348 differences in the common type.

349

350 In golden retrievers, sex and intranasal oxytocin treatment (part of the experiment for which the 351 dogs were originally recruited) were included in the models. In the analyses for both SNP1 and

352 SNP2, sex had an effect on the duration dogs spent in the owner zone where males spent

353 significantly more time with their owner than females $\left(F_{1,56}=6.590, p=0.013\right.$ for SNP1 model

354 and $F_{1,55}=7.374, p=0.009$ for SNP2 model; males $35.02 \pm 7.986$ vs. females $16.72 \pm 3.921$ ).

355 Additionally, in analyses for both SNPs, intranasal oxytocin treatment significantly decreased the

356 duration $\left(\mathrm{F}_{1,56}=15.797, \mathrm{p}<0.001\right.$ and $\mathrm{F}_{1,55}=22.377, \mathrm{p}<0.001$; oxytocin $0.24 \pm 0.109$ vs.

357 control $1.75 \pm 0.591)$ and frequency $\left(F_{1,56}=9.705, p=0.003\right.$ and $F_{1,55}=12.305, p=0.001$;

358 oxytocin $0.97 \pm 0.481$ vs. control $4.20 \pm 1.603$ ) of experimenter physical contact seeking as well 359 as the frequency of owner physical contact $\left(F_{1,56}=8.137, p=0.006\right.$ and $F_{1,55}=5.437, p=0.023$;

360 oxytocin $0.71 \pm 0.377$ vs. control $1.67 \pm 0.615)$.

361 
362 For the Labradors, sex and type were included in the models. In the models for both SNP1 and

363 SNP2, the difference between males and females for the duration of gazing at their owner was

364 significant where males looked for a longer time $\left(F_{1,90}=7.667, p=0.004\right.$ and $F_{1,93}=13.995, p<$

$3650.001 ; 10.19 \pm 2.72$ vs. $4.42 \pm 0.73$ seconds for males and females respectively). There were

366 many differences between the types. In the models for both SNPs, the frequency of owner and

367 experimenter zone were significant as well as the duration of gazing at the owner and frequency

368 and duration of owner physical contact. Field type Labradors visited the experimenter zone at a

369 higher frequency $\left(\mathrm{F}_{1,92}=9.046, \mathrm{p}=0.003\right.$ and $\mathrm{F}_{1,94}=4.821, \mathrm{p}=0.031 ; 3.27 \pm 0.37$ vs. $2.12 \pm$

$3700.22)$ as well as the owner zone $\left(F_{1,92}=18.153, p<0.001\right.$ and $F_{1,94}=10.559, p=0.002 ; 4.21 \pm$

3710.43 vs. $2.51 \pm 0.23$ times $)$. The field type gazed longer at their owner $\left(\mathrm{F}_{1,91}=10.475, \mathrm{p}=0.002\right.$

372 and $\mathrm{F}_{1,93}=25.596, \mathrm{p}<0.001 ; 5.74 \pm 0.92$ vs. $3.16 \pm 0.50$ seconds) and were in physical contact

373 with their owner both more often $\left(F_{1,92}=8.065, p=0.006\right.$ and $F_{1,94}=20.862, p<0.001 ; 0.77 \pm$

3740.17 vs. $0.29 \pm 0.10)$ and for a longer time $\left(F_{1,90}=15.910, p<0.001\right.$ and $F_{1,94}=9.025, p=0.003$;

$3750.70 \pm 0.19$ vs. $0.09 \pm 0.04)$. Additionally, in the model for SNP1, there were significant

376 differences between the types in frequency and duration of gazing at the experimenter as well as

377 frequency of owner gazing. The field type gazed both longer and more often at the experimenter

$378\left(\mathrm{~F}_{1,91}=10.475, \mathrm{p}=0.002\right.$ and $\left.\mathrm{F}_{1,91}=7.679, \mathrm{p}=0.007\right)$ and more often at their owner $\left(\mathrm{F}_{1,91}=\right.$

$37920.208, \mathrm{p}>0.001)$. The means of the duration and frequency for looking at experimenter were

$3805.74 \pm 0.92$ seconds and $4.02 \pm 0.49$ times in field type versus $3.16 \pm 0.50$ seconds and $2.63 \pm$

3810.34 in the common type. For the frequency of looking at owner, the means were $6.52 \pm 0.82$

382 versus $3.00 \pm 0.33$ times.

383

384 DISCUSSION 
385 In a previous genome-wide association study on beagles tested in the unsolvable problem 386 paradigm, Persson et al. (2016) identified two SNPs on chromosome 26, BICF2G630798942 387 (SNP1) and BICF2S23712114 (SNP2), associated with social interactions directed towards

388 humans. Here we show that both SNPs are also associated with human-directed social behaviour 389 in two additional dog breeds, golden and Labrador retriever. We also show that genotype 390 frequencies for the two SNPs differ between wolves and dogs, between breeds and between 391 recently selected breed types. Thus, these loci could have been affected by selection during 392 domestication as well as during breed formations. This suggests that selection of favourable 393 alleles in the genomic region of the SNPs may have been an important part of dog domestication. 394

395 In a population of laboratory beagles, Persson et al. (2016) found a significant association 396 between SNP1 and the duration of physical contact and duration of human proximity.

397 Additionally, a suggestive association was found between SNP2 and the duration of human 398 proximity. It is important to stress that these SNPs are not causative for the behaviour differences 399 but rather linked to the specific causal loci. SNP1 and SNP2 are both located on chromosome 26, 400 and within the linkage disequilibrium regions five possible associated genes are present. The 401 marker SNP1 is located in an intron of the gene SEZ6L and there are no other genes present in 402 the same linkage block. SNP2 is located in an intron of the gene $A R V C F$ and three additional 403 genes are in linkage: COMT, TXNRD2, and TANGO2. Previously, SEZ6L, ARVCF, COMT and 404 TXNRD2 have been associated with social disorders and schizophrenia in humans (Chapman et 405 al. 2015; Mas et al. 2010; Sanders et al. 2005; Xu et al. 2013). 406 
407 In the present study, we verify that the association between these genomic regions and human-

408 directed social behaviour are not specific to the previously studied beagles. Similar effects were

409 found in two other breeds, Labrador and golden retrievers, tested in the same unsolvable problem

410 task as the beagles. The genotype of SNP1 had an effect on physical contact seeking with both

411 experimenter and owner in the golden retriever and was associated with a difference in owner

412 gazing between Labrador types. The genotype of SNP2 was primarily associated with eye

413 contact seeking with the experimenter as well as owner in both golden and Labrador retrievers.

414 In the Labradors this effect differed between types where the only field type individuals carrying

415 the AA-genotype were gazing more. Additionally, SNP2 was associated with experimenter

416 proximity seeking in both breeds and owner proximity seeking in only Labradors. Finally, an

417 association was found between SNP2 and owner physical contact seeking in golden retrievers

418 but not in Labradors. Genotype and sex interactions were identified in the beagles for SNP1

419 (Persson et al. 2016) but this was not present in the retrievers.

420

421 In addition to SEZ6L, ARVCF and COMT, there are other genes suggested to be associated with

422 dogs' human-directed social behaviour. Previous research has found associations between

423 polymorphisms in the oxytocin receptor gene and social behaviour both during problem solving

424 and in additional situations (Kis et al. 2014; Persson et al. 2017). The oxytocin receptor gene has

425 also been associated with successful training of detection dogs (Konno et al. 2018). Another gene

426 of interest is the dopamine receptor D4 gene that has been associated with gazing towards

427 humans (Hori et al. 2013). Additionally, vonHoldt et al. (2017) investigated a candidate region

428 associated to Williams-Beuren syndrome (WBS) in humans, which is causing hyper-social 
429 behaviour amongst other effects. It was found that structural variants in this region were also

430 associated with extreme sociability in dogs.

431

432 During the course of domestication, dogs seem to have evolved impressive interspecific 433 cooperation skills with humans (Jensen et al. 2016; Miklósi \& Topál 2013). For example, 434 comparative studies have shown that dogs have a higher sociability in general than wolves 435 (Bentosela et al. 2016) and, specifically, that dogs seek more human contact when faced with a 436 problem than wolves do (Heberlein et al. 2016; Miklósi et al. 2003; Udell 2015). It seems that 437 genetic variants contributing to human-directed social abilities have been selected during 438 domestication and, thus, the two genomic regions investigated in the present study may have 439 been targeted. Variation in sociability towards humans has a significant genetic component, 440 which has been shown by heritability estimates (Persson et al. 2015; Sundman et al. 2016; van

441 der Waaij et al. 2008; Wilsson \& Sundgren 1998) and this is a requirement for selection. Wolves 442 were found to be fixed for the C-allele on SNP1 whereas there was a variation in SNP2. The 443 former polymorphism may thus not exist or is rare among wolves and could even have appeared 444 after the split with dogs, whereas the latter is present in both species. However, as this current 445 study has investigated the SNP genotypes in only a very limited sample of Scandinavian wolves, 446 these results should be cautiously interpreted. A recent study describing the genetic architecture 447 of a dog x wolf crossbreed, the Czechoslovakian Wolfdog, found regions containing excess of 448 wolf and dog ancestry genes respectively (Caniglia et al. 2018). The Czechoslovakian Wolfdog 449 derives from a cross between Carpathian wolves and German shepherd dogs and, even though it 450 shares many morphological features with the wolf, it shows mostly dog-like behavioural 
451 phenotypes. Interestingly the SEZ6L, ARVCF and COMT genes were all detected within regions

452 of excess dog ancestry.

453

454 When using an unsolvable problem paradigm to study human-directed social behaviour we

455 should also consider the dogs' persistence to solve the problem and their food motivation.

456 Previous studies have, for example, found a negative correlation between persistence and eye-

457 contact duration (Brubaker et al. 2017), and that more persistent dogs show a longer latency until

458 they gaze at the present human (Marshall-Pescini et al. 2017). On the other hand, in both Persson

459 et al. (2015) and Sundman et al. (2018), test-setup interactions form a component separate from

460 social behaviours in a principal component analysis. It is difficult to disentangle sociability from

461 persistence and food motivation when using the unsolvable problem paradigm. However, neither

462 of the two SNPs in the present study were associated with the duration the dogs spent in

463 proximity of the test-setup, and thus, they seem to be associated with human-directed social

464 behaviour rather than persistence.

465

466 Previous studies have reported breed differences in behaviours related to human communication

467 (Passalacqua et al. 2011; Sundman et al. 2018; Udell et al. 2014). We can study recent selection

468 by examining established breeds recently diverged into two types due to different breeding goals;

469 for example, dogs suitable for field-work versus pet and conformation dogs. The Labrador

470 retriever is a breed clearly divided into two types. Pedigrees as well as morphology and

471 behaviour distinguish the common type from the field type (Sundman et al. 2018; Sundman et al.

472 2016). Specifically, Sundman et al. (2018) compared the types in the unsolvable problem task

473 and found several behavioural differences. During recent selection, it seems that the field type 
474 has increased its human-contact seeking behaviour in comparison to the common type, although

475 environmental causes cannot be discarded. Likewise, in the present study, we found differences

476 in allele frequencies between the types for both SNP1 and SNP2. These genetic markers have

477 thus been affected by recent selection in two selection lines of dogs that also differ in social

478 abilities, lending further support to the association between the genomic region and human-

479 directed social behaviour.

480

\section{CONCLUSIONS}

482 Our results verify the associations between human-directed social behaviour and the SNPs

483 BICF2G630798942 and BICF2S23712114 on canine chromosome 26. We suggest that these loci

484 could have been affected by domestication and selection for sociality in dogs and that genetic

485 variants linked to the SNPs may have been targeted during domestication. Hence, genes within

486 the linkage disequilibrium of these genetic markers are of high interest for further investigation

487 of the genetics behind the impressive social skills of dogs.

488

489 ACKNOWLEDGEMENTS

490 We wish to thank the enthusiastic dog owners who allowed their dogs to participate in this project as 491 well as Borås Zoo and Kolmården Wildlife Park for kindly providing us with wolf samples. Special 492 thanks to Therese Hård at Borås Zoo for all your help, and to Lina S V Roth and Enya van Poucke, 493 Linköping University, for support and proof reading of the manuscript. 
495

496

497

498

499

500

501

502

503

504

505

506

507

508

509

510

511

512

513

514

515

516

517

518

519

520

521

522

523

524

525

526

\section{REFERENCES}

Andics A, Gabor A, Gacsi M, Farago T, Szabo D, and Miklosi A. 2016.

Neural mechanisms for lexical processing in dogs. Science 353:1030-1032. 10.1126/science.aaf3777

Bentosela M, Wynne CD, D'Orazio M, Elgier A, and Udell MA. 2016. Sociability and gazing toward humans in dogs and wolves: Simple behaviors with broad implications. Journal of the Experimental Analysis of Behavior 105:68-75. 10.1002/jeab.191

Brubaker L, Dasgupta S, Bhattacharjee D, Bhadra A, and Udell MA. 2017. Differences in problem-solving between canid populations: Do domestication and lifetime experience affect persistence? Anim Cogn 20:717-723.

Caniglia R, Fabbri E, Hulva P, Bolfikova BC, Jindrichova M, Stronen AV, Dykyy I, Camatta A, Carnier P, Randi E, and Galaverni M. 2018. Wolf outside, dog inside? The genomic make-up of the Czechoslovakian Wolfdog. BMC Genomics 19. ARTN 533 10.1186/s12864-018-4916-2

Chapman NH, Nato AQ, Jr., Bernier R, Ankenman K, Sohi H, Munson J, Patowary A, Archer M, Blue EM, Webb SJ, Coon H, Raskind WH, Brkanac Z, and Wijsman EM. 2015. Whole exome sequencing in extended families with autism spectrum disorder implicates four candidate genes. Hum Genet. 10.1007/s00439-015-1585-y

Gacsi M, Gyori B, Viranyi Z, Kubinyi E, Range F, Belenyi B, and Miklosi A. 2009. Explaining Dog Wolf Differences in Utilizing Human Pointing Gestures: Selection for Synergistic Shifts in the Development of Some Social Skills. Plos One 4. ARTN e6584

DOI 10.1371/journal.pone.0006584

Hare B, and Tomasello M. 1999. Domestic dogs (Canis familiaris) use human and conspecific social cues to locate hidden food. J Comp Psychol 113:173-177. Doi 10.1037/0735-7036.113.2.173 Hare B, and Tomasello M. 2005. Human-like social skills in dogs? Trends Cogn Sci 9:439-444. 10.1016/j.tics.2005.07.003 
527 Heberlein MTE, Turner DC, Range F, and Virányi Z. 2016. A comparison

528

529

530

531

532

533

534

535

536

537

538

539

540

541

542

543

544

545

546

547

548

549

550

551

552

553

554

555

556

557

558

559

between wolves, Canis lupus, and dogs, Canis familiaris, in

showing behaviour towards humans. Animal Behaviour 122:59-66. http://dx.doi.org/10.1016/j.anbehav.2016.09.023

Hori Y, Kishi H, Inoue-Murayama M, and Fujita K. 2013. Dopamine receptor $\mathrm{D} 4$ gene (DRD4) is associated with gazing toward humans in domestic dogs (Canis familiaris). Open Journal of Animal Sciences 3:54.

Horn L, Huber L, and Range F. 2013. The Importance of the Secure Base Effect for Domestic Dogs - Evidence from a Manipulative ProblemSolving Task. Plos One 8. ARTN e65296

DOI 10.1371/journal.pone.0065296

Jensen $P$, Persson ME, Wright $D$, Johnsson $M$, Sundman A-S, and Roth LSV. 2016. The Genetics of How Dogs Became Our Social Allies. Current Directions in Psychological Science 25:334-338. 10.1177/0963721416657050

Kis A, Bence M, Lakatos G, Pergel E, Turcsan B, Pluijmakers J, Vas J, Elek Z, Bruder I, Foldi L, Sasvari-Szekely M, Miklosi A, Ronai Z, and Kubinyi E. 2014. Oxytocin Receptor Gene Polymorphisms Are Associated with Human Directed Social Behavior in Dogs (Canis familiaris). Plos One 9. ARTN e83993

DOI 10.1371/journal.pone.0083993

Konno A, Inoue-Murayama M, Yabuta S, Tonoike A, Nagasawa M, Mogi K, and Kikusui T. 2018. Effect of Canine Oxytocin Receptor Gene Polymorphism on the Successful Training of Drug Detection Dogs. Journal of Heredity 1:7.

Lakatos G, Gácsi M, Topál J, and Miklósi Á. 2012. Comprehension and utilisation of pointing gestures and gazing in dog-human communication in relatively complex situations. Anim Cogn 15:201-213. 10.1007/s10071-011-0446-x

Lindblad-Toh K, Wade CM, Mikkelsen TS, Karlsson EK, Jaffe DB, Kamal M, Clamp M, Chang JL, Kulbokas EJ, Zody MC, Mauceli E, Xie XH, Breen M, Wayne RK, Ostrander EA, Ponting CP, Galibert F, Smith 
560

561

562

563

564

565

566

567

568

569

570

571

572

573

574

575

576

577

578

579

580

581

582

583

584

585

586

587

588

589

590

591

592

DR, deJong PJ, Kirkness E, Alvarez P, Biagi T, Brockman W, Butler J, Chin CW, Cook A, Cuff J, Daly MJ, DeCaprio D, Gnerre S, Grabherr M, Kellis M, Kleber M, Bardeleben C, Goodstadt L, Heger A, Hitte C, Kim L, Koepfli KP, Parker HG, Pollinger JP, Searle SMJ, Sutter NB, Thomas R, Webber C, Lander ES, and Plat BIGS. 2005. Genome sequence, comparative analysis and haplotype structure of the domestic dog. Nature 438:803-819. Doi 10.1038/Nature04338

Marshall-Pescini S, Colombo E, Passalacqua C, Merola I, and PratoPrevide E. 2013. Gaze alternation in dogs and toddlers in an unsolvable task: evidence of an audience effect. Anim Cogn 16:933-943. Doi 10.1007/S10071-013-0627-X

Marshall-Pescini S, Rao A, Virányi Z, and Range F. 2017. The role of domestication and experience in 'looking back'towards humans in an unsolvable task. Sci Rep 7:46636.

Mas S, Bernardo M, Gasso P, Alvarez S, Garcia-Rizo C, Bioque M, Kirkpatrick B, and Lafuente A. 2010. A functional variant provided further evidence for the association of ARVCF with schizophrenia. Am J Med Genet B Neuropsychiatr Genet 153B:1052-1059. 10.1002/ajmg.b.31073

Miklósi Á, Kubinyi E, Topál J, Gácsi M, Virányi Z, and Csányi V. 2003. A simple reason for a big difference: wolves do not look back at humans, but dogs do. Current Biology 13:763-766.

Miklosi A, Polgardi R, Topal J, and Csanyi V. 2000. Intentional behaviour in dog-human communication: an experimental analysis of "showing" behaviour in the dog. Anim Cogn 3:159-166.

Miklósi Á, and Topál J. 2013. What does it take to become 'best friends'? Evolutionary changes in canine social competence. Trends Cogn Sci 17:287-294.

Muller CA, Schmitt K, Barber AL, and Huber L. 2015. Dogs can discriminate emotional expressions of human faces. Current Biology 25:601-605. 10.1016/j.cub.2014.12.055

Nagasawa M, Mitsui S, En S, Ohtani N, Ohta M, Sakuma Y, Onaka T, Mogi K, and Kikusui T. 2015. Social evolution. Oxytocin-gaze 
593

594

595

596

597

598

599

600

601

602

603

604

605

606

607

608

609

610

611

612

613

614

615

616

617

618

619

620

621

622

623

624

625

positive loop and the coevolution of human-dog bonds. Science 348:333-336. 10.1126/science.1261022

Passalacqua C, Marshall-Pescini S, Barnard S, Lakatos G, Valsecchi P, and Previde EP. 2011. Human-directed gazing behaviour in puppies and adult dogs, Canis lupus familiaris. Animal Behaviour 82:1043-1050. Doi 10.1016/J.Anbehav.2011.07.039

Persson ME, Roth LSV, Johnsson M, Wright D, and Jensen P. 2015. Human-directed social behaviour in dogs shows significant heritability. Genes Brain and Behavior 14:337-344.

10.1111/gbb.12194

Persson ME, Trottier AJ, Belteky J, Roth LSV, and Jensen P. 2017. Intranasal oxytocin and a polymorphism in the oxytocin receptor gene are associated with human-directed social behavior in golden retriever dogs. Hormones and Behavior 95:85-93. 10.1016/j.yhbeh.2017.07.016

Persson ME, Wright D, Roth LS, Batakis P, and Jensen P. 2016. Genomic Regions Associated With Interspecies Communication in Dogs Contain Genes Related to Human Social Disorders. Sci Rep 6:33439. 10.1038/srep33439

Qayyum A, C CZ, Hirata Y, A KT, Cheema S, Nowrouzi B, Beitchman JH, and Kennedy L. 2015. The Role of the Catechol-oMethyltransferase (COMT) GeneVal158Met in Aggressive Behavior, a Review of Genetic Studies. Curr Neuropharmacol 13:802-814.

Range F, and Viranyi Z. 2015. Tracking the evolutionary origins of doghuman cooperation: the "Canine Cooperation Hypothesis". Frontiers in Psychology 5. ARTN 1582

10.3389/fpsyg.2014.01582

Sanders AR, Rusu I, Duan J, Vander Molen JE, Hou C, Schwab SG, Wildenauer DB, Martinez M, and Gejman PV. 2005. Haplotypic association spanning the 22q11.21 genes COMT and ARVCF with schizophrenia. Mol Psychiatry 10:353-365.

10.1038/sj.mp.4001586 
626

627

628

629

630

631

632

633

634

635

636

637

638

639

640

641

642

643

644

645

646

647

648

649

650

651

652

653

654

655

656

657

Sim K, Chan WY, Woon PS, Low HQ, Lim L, Yang GL, Lee J, Chong SA, Sitoh YY, Chan YH, Liu J, Tan EC, Williams H, and Nowinski WL. 2012. ARVCF genetic influences on neurocognitive and neuroanatomical intermediate phenotypes in Chinese patients with schizophrenia. J Clin Psychiatry 73:320-326. 10.4088/JCP.10m06491

Soproni K, Miklosi A, Topal J, and Csanyi V. 2001. Comprehension of human communicative signs in pet dogs (Canis familiaris). J Comp Psychol 115:122-126. Doi 10.1037//0735-7036.115.2.122

Sundman A-S, Persson ME, Grozelier A, Halldén L-L, Jensen P, and Roth LSV. 2018. Understanding of human referential gestures is not correlated to human-directed social behaviour in Labrador retrievers and German shepherd dogs. Applied Animal Behaviour Science. https://doi.org/10.1016/j.applanim.2017.12.017

Sundman AS, Johnsson M, Wright D, and Jensen P. 2016. Similar recent selection criteria associated with different behavioural effects in two dog breeds. Genes Brain and Behavior 15:750-756. 10.1111/gbb.12317

Sutter NB, Eberle MA, Parker HG, Pullar BJ, Kirkness EF, Kruglyak L, and Ostrander EA. 2004. Extensive and breed-specific linkage disequilibrium in Canis familiaris. Genome Research 14:23882396.

Topal J, Gacsi M, Miklosi A, Viranyi Z, Kubinyi E, and Csanyi V. 2005. Attachment to humans: a comparative study on hand-reared wolves and differently socialized dog puppies. Animal Behaviour 70:1367-1375. Doi 10.1016/J.Anbehav.2005.03.025

Topal J, Miklosi A, Csanyi V, and Doka A. 1998. Attachment behavior in dogs (Canis familiaris): A new application of Ainsworth's (1969) Strange Situation Test. J Comp Psychol 112:219-229. Doi 10.1037/0735-7036.112.3.219

Udell MA. 2015. When dogs look back: inhibition of independent problem-solving behaviour in domestic dogs (Canis lupus 
658

659

660

661

662

663

664

665

666

667

668

669

670

671

672

673

674

675

676

677

678

679

680

681

682

683

684

685

familiaris) compared with wolves (Canis lupus). Biology Letters 11:20150489.

Udell MAR, Ewald M, Dorey NR, and Wynne CDL. 2014. Exploring breed differences in dogs (Canis familiaris): does exaggeration or inhibition of predatory response predict performance on humanguided tasks? Animal Behaviour 89:99-105. http://dx.doi.org/10.1016/j.anbehav.2013.12.012

van der Waaij EH, Wilsson E, and Strandberg E. 2008. Genetic analysis of results of a Swedish behavior test on German Shepherd Dogs and Labrador Retrievers. J Anim Sci 86:2853-2861. 10.2527/jas.2007-0616

Wilsson E, and Sundgren PE. 1998. Behaviour test for eight-week old puppies - heritabilities of tested behaviour traits and its correspondence to later behaviour. Applied Animal Behaviour Science 58:151-162. Doi 10.1016/S0168-1591(97)00093-2 vonHoldt BM, Shuldiner E, Koch IJ, Kartzinel RY, Hogan A, Brubaker L, Wanser S, Stahler D, Wynne CDL, Ostrander EA, Sinsheimer JS, and Udell MAR. 2017. Structural variants in genes associated with human Williams-Beuren syndrome underlie stereotypical hypersociability in domestic dogs. Science Advances 3. 10.1126/sciadv.1700398

Xu C, Mullersman JE, Wang L, Bin Su B, Mao C, Posada Y, Camarillo C, Mao Y, Escamilla MA, and Wang KS. 2013. Polymorphisms in seizure 6-like gene are associated with bipolar disorder I: evidence of gene x gender interaction. J Affect Disord 145:95-99. 10.1016/j.jad.2012.07.017 


\section{Table $\mathbf{1}$ (on next page)}

Ethogram of the behaviours analysed in the unsolvable problem task.

For each behaviour, duration and frequency were scored. The behaviours were not mutually exclusive. 
1 Table 1. Ethogram of the behaviours analysed in the unsolvable problem task. Duration and

2 frequency of the behaviours were scored. Zone behaviours are mutually exclusive.

\begin{tabular}{ll}
\hline Behaviour & Description \\
\hline Experimenter zone & Dogs' head is within one body length of the experimenter \\
Owner zone & Dogs' head is within one body length of the owner \\
Experimenter gaze & The dog directs its eyes towards the face of the experimenter \\
Owner gaze & The dog directs its eyes towards the face of the owner \\
Experimenter physical contact & The dog in physical contact with the experimenter \\
Owner physical contact & The dog is in physical contact with the owner \\
Duration test-setup & the test-setup
\end{tabular}

3 


\section{Table 2 (on next page)}

Generalized linear mixed models analysis for behavioural variables and SNP genotype in golden retrievers

The models also included sex and treatment (intranasal oxytocin) as fixed factors. 
1 Table 2. Generalized linear mixed models analysis for behavioural variables and SNP genotype in golden retrievers. The models also

2 included sex and treatment (intranasal oxytocin) as fixed factors.

\begin{tabular}{|c|c|c|c|c|c|c|c|c|c|c|c|c|}
\hline \multirow[t]{2}{*}{ Behaviour } & \multirow[t]{2}{*}{ Df1 } & \multirow[t]{2}{*}{ Df2 } & \multicolumn{2}{|c|}{ SNP1 } & \multicolumn{2}{|c|}{ Sex } & \multicolumn{2}{|c|}{ Treatment } & \multicolumn{2}{|c|}{ SNP1 * sex } & SNP1 $*$ treatment & \multirow[t]{2}{*}{ Distribution } \\
\hline & & & $\mathrm{F}$ & $P$ & $\mathrm{~F}$ & $P$ & $\mathrm{~F}$ & $P$ & $\mathrm{~F}$ & $P$ & $\mathrm{~F}$ & \\
\hline $\begin{array}{l}\text { Duration experimenter } \\
\text { look } \\
\text { Frequency experimenter }\end{array}$ & 1 & 56 & 1,723 & 0,188 & 7,382 & 0,009 & 0,058 & 0,81 & & NA & NA & Gamma log \\
\hline $\begin{array}{l}\text { look } \\
\text { Duration experimenter }\end{array}$ & 1 & 56 & 0,575 & 0,566 & 1,537 & 0,22 & 0,615 & 0,436 & & NA & NA & $\begin{array}{l}\text { Gamma log } \\
\text { Normal }\end{array}$ \\
\hline & 1 & 56 & 0,096 & 0,908 & 1,742 & 0,192 & 0,488 & 0,488 & & NA & NA & identity \\
\hline zone & 1 & 56 & 0,292 & 0,748 & 1,112 & 0,296 & 0,085 & 0,771 & & NA & NA & Gamma log \\
\hline $\begin{array}{l}\text { Duration experimenter } \\
\text { contact }\end{array}$ & 1 & 56 & 2,117 & 0,13 & 0,569 & 0,454 & $\begin{array}{l}15,79 \\
7\end{array}$ & $\begin{array}{l}>0,00 \\
1\end{array}$ & & NA & NA & Gamma log \\
\hline $\begin{array}{l}\text { Frequency experimenter } \\
\text { contact }\end{array}$ & 1 & 56 & 4,339 & 0,018 & 0,697 & 0,407 & 9,705 & 0,003 & & NA & NA & Gamma log \\
\hline Duration owner look & 1 & 56 & 1,68 & 0,196 & 0,006 & 0,938 & 0,274 & 0,603 & & NA & NA & Gamma log \\
\hline Frequency owner look & 2 & 56 & 1,26 & 0,292 & 0,002 & 0,965 & 2,356 & 0,13 & & NA & NA & Gamma log \\
\hline Duration owner zone & 1 & 56 & 0,451 & 0,639 & 6,59 & 0,013 & 1,194 & 0,279 & & NA & NA & Gamma log \\
\hline Frequency owner zone & 1 & 56 & 1,956 & 0,151 & 2,197 & 0,144 & 0,292 & 0,663 & & NA & NA & Gamma log \\
\hline Duration owner contact & 2 & 56 & 4,389 & 0,017 & 1,095 & 0,3 & 2,93 & 0,092 & & NA & NA & Gamma log \\
\hline Frequency owner contact & 2 & 56 & 6,996 & 0,002 & 3,175 & 0,08 & 8,137 & 0,006 & & NA & NA & Gamma log \\
\hline Duration test-setup & 2 & 56 & 0,457 & 0,636 & 3,246 & 0,077 & 0,217 & 0,643 & & NA & NA & Gamma log \\
\hline Behaviour & Df1 & Df2 & \multicolumn{2}{|c|}{ SNP2 } & \multicolumn{2}{|c|}{ Sex } & \multicolumn{2}{|c|}{ Treatment } & \multicolumn{2}{|c|}{ SNP2 * sex } & SNP2 $*$ treatment & Distribution \\
\hline & & & $\mathrm{F}$ & $P$ & $\mathrm{~F}$ & $P$ & $\mathrm{~F}$ & $P$ & $\mathrm{~F}$ & $P$ & $P$ & \\
\hline $\begin{array}{l}\text { Duration experimenter } \\
\text { look } \\
\text { Frequency experimenter }\end{array}$ & 1 & 55 & 1,023 & 0,366 & 7,682 & 0,008 & 0,013 & 0,909 & & NA & NA & Gamma log \\
\hline $\begin{array}{l}\text { look } \\
\text { Duration experimenter }\end{array}$ & 2 & 55 & 3,243 & 0,047 & 2,957 & 0,091 & 0,771 & 0,384 & & NA & NA & $\begin{array}{l}\text { Gamma log } \\
\text { Normal }\end{array}$ \\
\hline $\begin{array}{l}\text { zone } \\
\text { Frequency experimenter }\end{array}$ & 2 & 55 & 3,304 & 0,044 & 1,655 & 0,204 & 0,552 & 0,461 & & NA & NA & identity \\
\hline zone & 1 & 55 & 0,97 & 0,386 & 1,185 & 0,281 & 0,051 & 0,822 & & NA & NA & Gamma log \\
\hline
\end{tabular}




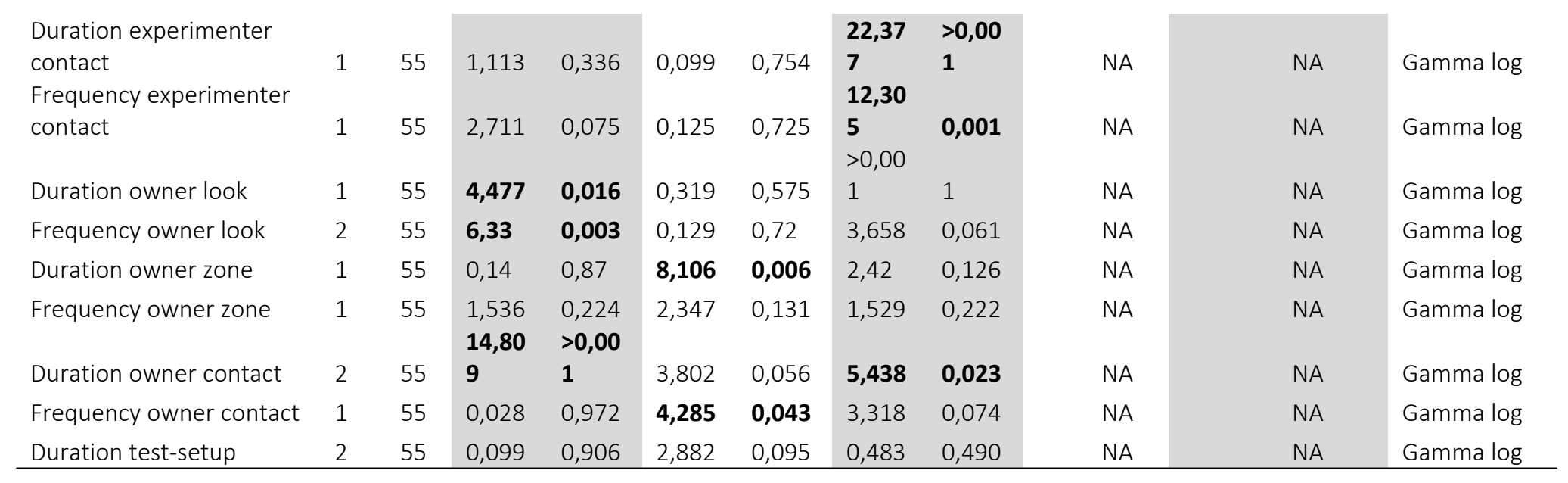




\section{Table 3(on next page)}

Generalized linear mixed models analysis for behavioural variables and SNP genotype in Labrador retrievers.

The models also included sex and type (common or field) as fixed factors. 
1 Table 3. Generalized linear mixed models analysis for behavioural variables and SNP genotype in Labrador retrievers. The models also 2 included sex and type (common or field) as fixed factors.

\begin{tabular}{|c|c|c|c|c|c|c|c|c|c|c|c|c|c|}
\hline \multirow{4}{*}{$\begin{array}{l}\text { Behaviour } \\
\text { Duration experimenter } \\
\text { look }\end{array}$} & \multirow[t]{2}{*}{ Df1 } & \multirow[t]{2}{*}{$\mathrm{Df} 2$} & \multicolumn{2}{|c|}{ SNP1 } & \multicolumn{2}{|c|}{ Sex } & \multicolumn{2}{|c|}{ Type } & \multicolumn{2}{|c|}{ SNP1 * sex } & \multicolumn{2}{|c|}{ SNP1 ${ }^{*}$ type } & \multirow[t]{2}{*}{ Distribution } \\
\hline & & & $\mathrm{F}$ & $P$ & $\mathrm{~F}$ & $P$ & $\mathrm{~F}$ & $P$ & $\mathrm{~F}$ & $P$ & $\mathrm{~F}$ & $P$ & \\
\hline & & & & & & & 10,47 & & & & & 0,09 & \\
\hline & 2 & 91 & 2,472 & 0,09 & 0,043 & 0,837 & 5 & 0,002 & & NA & 2,912 & 1 & Gamma log \\
\hline \multirow{2}{*}{$\begin{array}{l}\text { Frequency experimenter } \\
\text { look }\end{array}$} & & & & & & & & & & & & 0,08 & \\
\hline & 2 & 91 & 1,719 & 0,185 & 0,148 & 0,702 & 7,679 & 0,007 & & NA & 2,962 & 9 & Gamma log \\
\hline \multicolumn{14}{|l|}{ Duration experimenter } \\
\hline zone & 1 & 92 & 1,031 & 0,351 & 0,113 & 0,737 & 0,006 & 0,941 & & NA & & NA & Gamma log \\
\hline \multicolumn{14}{|l|}{ Frequency experimenter } \\
\hline zone & 1 & 92 & 1,09 & 0,34 & 0,698 & 0,406 & 9,046 & 0,003 & & NA & & NA & Gamma log \\
\hline \multicolumn{14}{|l|}{ Duration experimenter } \\
\hline \multicolumn{14}{|l|}{ Frequency experimenter } \\
\hline \multirow[t]{2}{*}{ contact } & 1 & 92 & 1,085 & 0,342 & 0,131 & 0,719 & 0,274 & 0,602 & & NA & & NA & Gamma log \\
\hline & & & & & & & 27,87 & $>0,00$ & & & 10,39 & 0,00 & \\
\hline \multirow[t]{2}{*}{ Duration owner look } & 2 & 90 & 0,953 & 0,39 & 8,82 & 0,004 & 8 & 1 & & NA & 4 & 2 & Gamma log \\
\hline & & & & & & & 20,20 & $>0,00$ & & & & 0,10 & \\
\hline \multirow[t]{2}{*}{ Frequency owner look } & 2 & 91 & 1,242 & 0,294 & 2,897 & 0,092 & 8 & 1 & & NA & 2,711 & 3 & Gamma log \\
\hline & 1 & 92 & 0.026 & 0.975 & 0.085 & 0.772 & 3,147 & 0.079 & & NA & & NA & $\begin{array}{l}\text { Normal identity } \\
\text { (logged) }\end{array}$ \\
\hline Duration owner zone & & & & & & & 18,15 & $>0,00$ & & & & & \\
\hline \multirow[t]{2}{*}{ Frequency owner zone } & 1 & 92 & 1,432 & 0,244 & 0,029 & 0,866 & 3 & 1 & & NA & & NA & Gamma log \\
\hline & & & & & & & & $>0,00$ & & & & & \\
\hline Duration owner contact & 1 & 90 & 0,034 & 0,966 & 0,211 & 0,647 & 15,91 & 1 & & NA & & NA & Gamma log \\
\hline Frequency owner contact & 1 & 92 & 0,268 & 0,765 & 0,177 & 0,675 & 8,065 & 0,006 & & NA & & NA & Gamma log \\
\hline Duration test-setup & 2 & 92 & 0,020 & 0,980 & 0,211 & 0,647 & 1,946 & 0,166 & & NA & & NA & Gamma log \\
\hline \multirow[t]{2}{*}{ Behaviour } & Df1 & Df2 & SNP2 & & Sex & & Type & & SN & sex & SNP2 & ype & Distribution \\
\hline & & & $\mathrm{F}$ & $P$ & $\mathrm{~F}$ & $\mathrm{P}$ & $\mathrm{F}$ & $P$ & $\mathrm{~F}$ & $P$ & $\mathrm{~F}$ & $P$ & \\
\hline \multirow{4}{*}{$\begin{array}{l}\text { Duration experimenter } \\
\text { look } \\
\text { Frequency experimenter } \\
\text { look }\end{array}$} & & & & & & & & & & & & 0,00 & \\
\hline & 2 & 93 & 3,365 & 0,07 & 0,087 & 0,769 & 0,056 & 0,813 & & NA & 7,796 & 6 & Gamma log \\
\hline & & & & & & & & & & & & 0,13 & \\
\hline & 2 & 93 & 3,025 & 0,085 & 0 & 0,992 & 0,122 & 0,728 & & NA & 2,314 & 2 & Gamma log \\
\hline
\end{tabular}




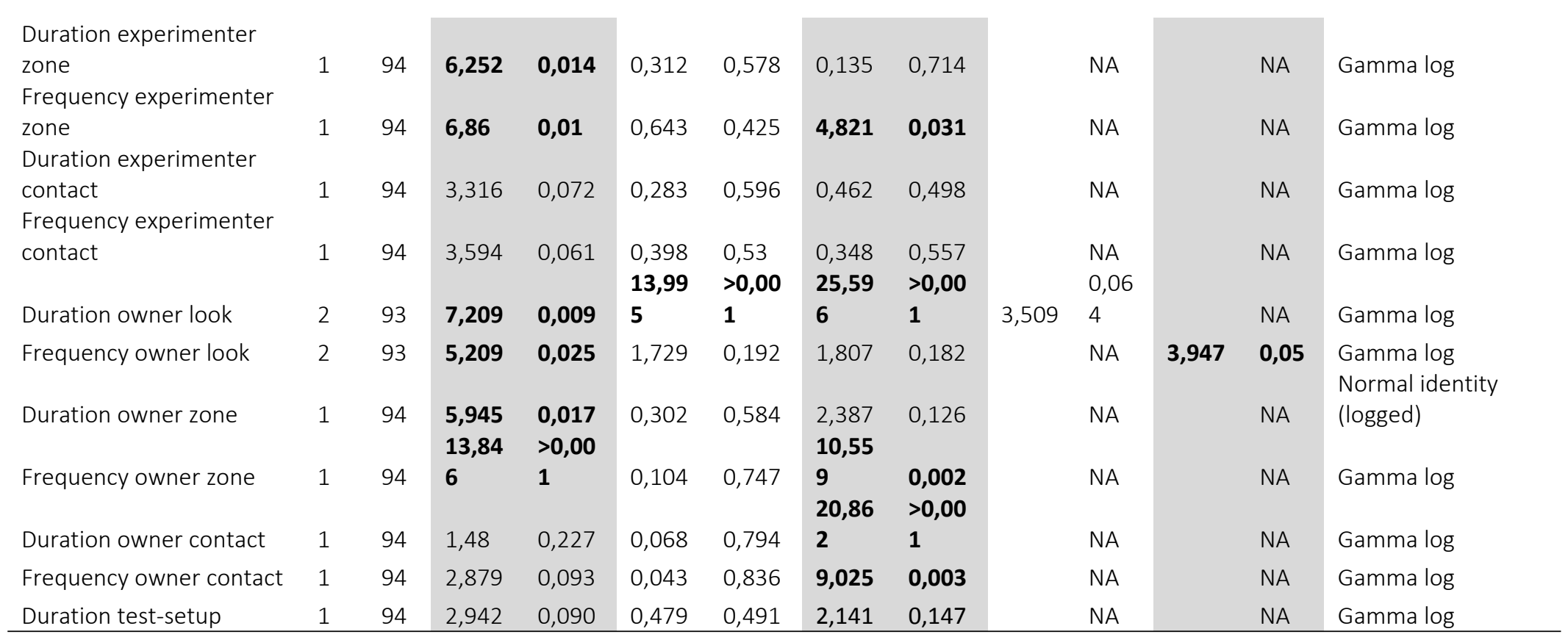

3 


\section{Figure 1}

The unsolvable task

A) Golden retriever dog interacting with the unsolvable task. B) The plastic tray measures 55 $\times 25 \mathrm{~cm}$, circular wells $7 \mathrm{~cm}$ in diameter and the plexiglass lids $10 \times 15 \mathrm{~cm}$. The left and right lid can be opened to access the treats. The middle lid cannot be opened, hence making the task unsolvable. Photo credit: Mia E. Persson 


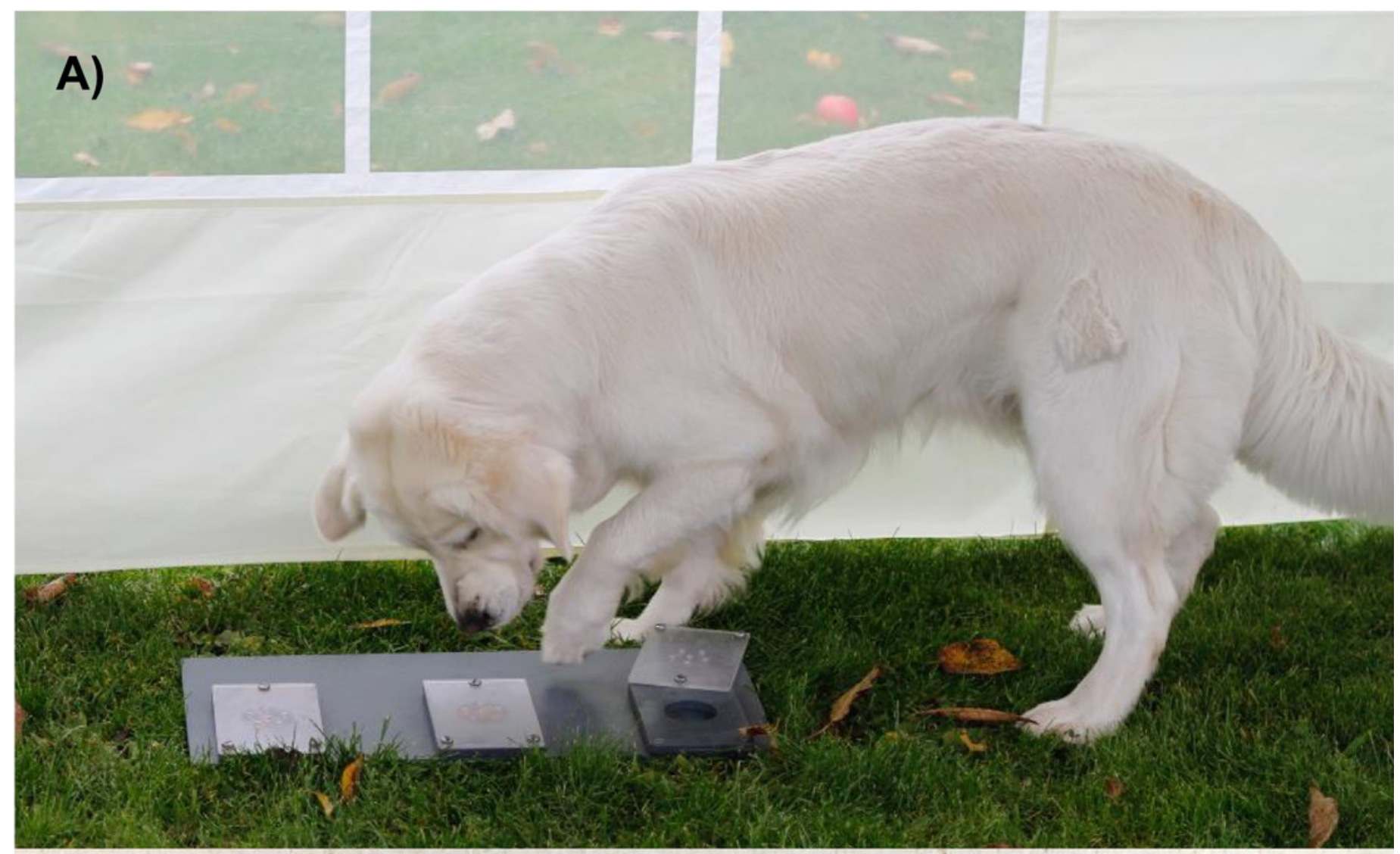

B)

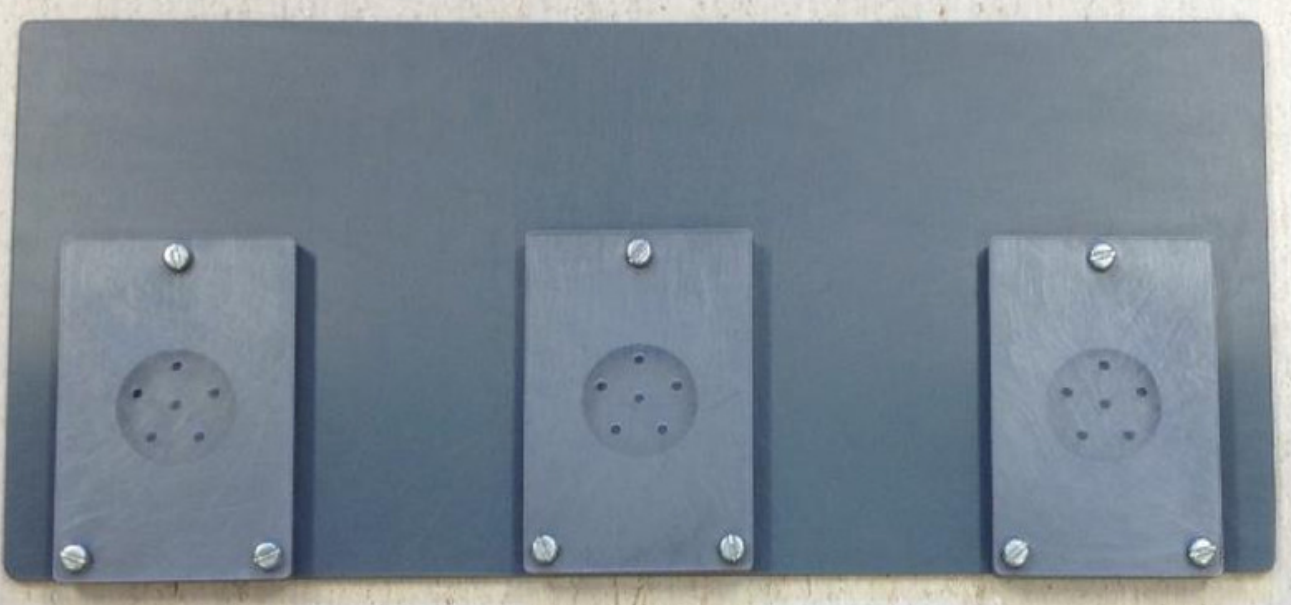


Figure 2

Allele frequencies

Allele frequencies for (A) the SNP BICF2G630798942 (SNP1) and (B) the SNP

BICF2S23712114 (SNP2) for Labrador retrievers (common and field type), golden retrievers and wolves.

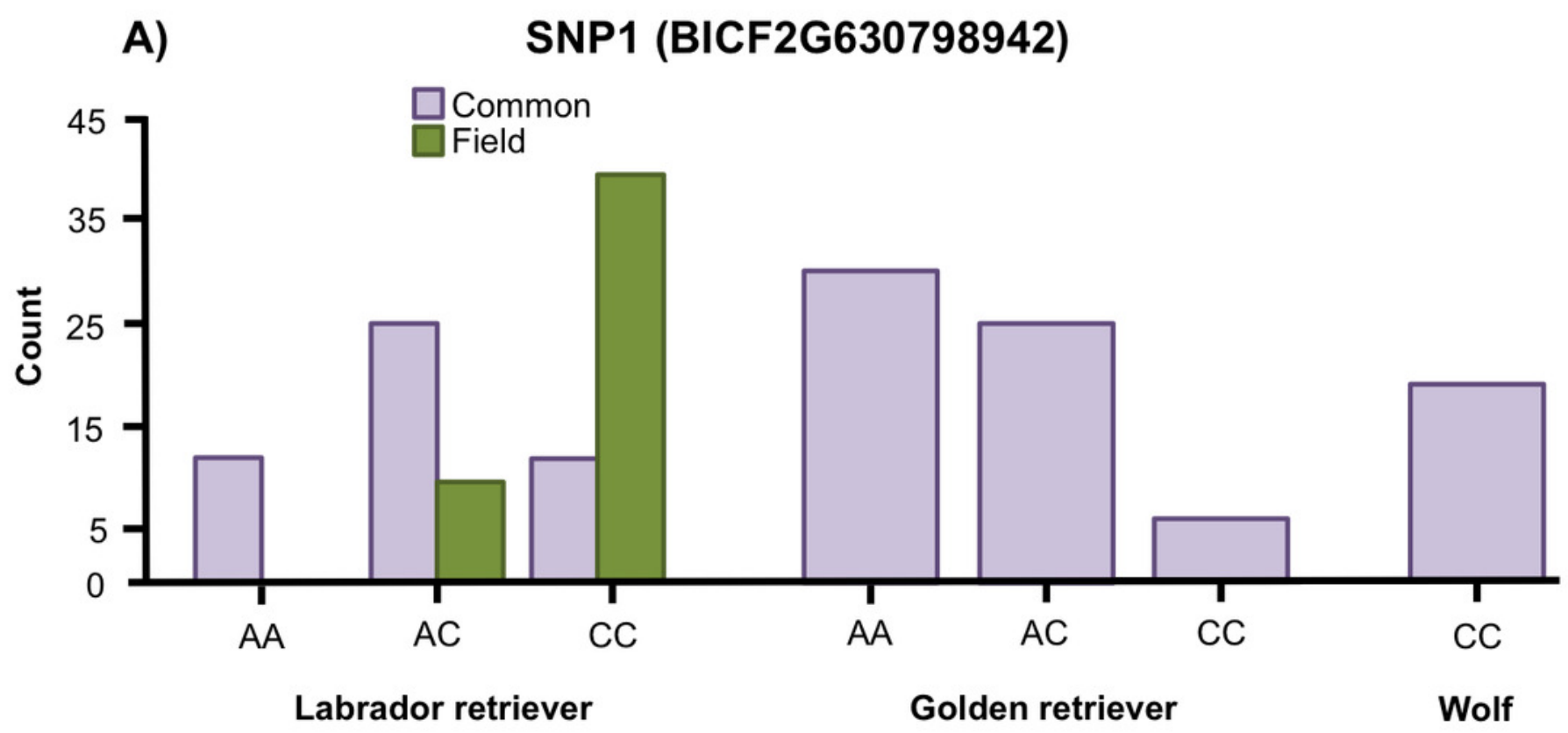

B)

SNP2 (BICF2S23712114)

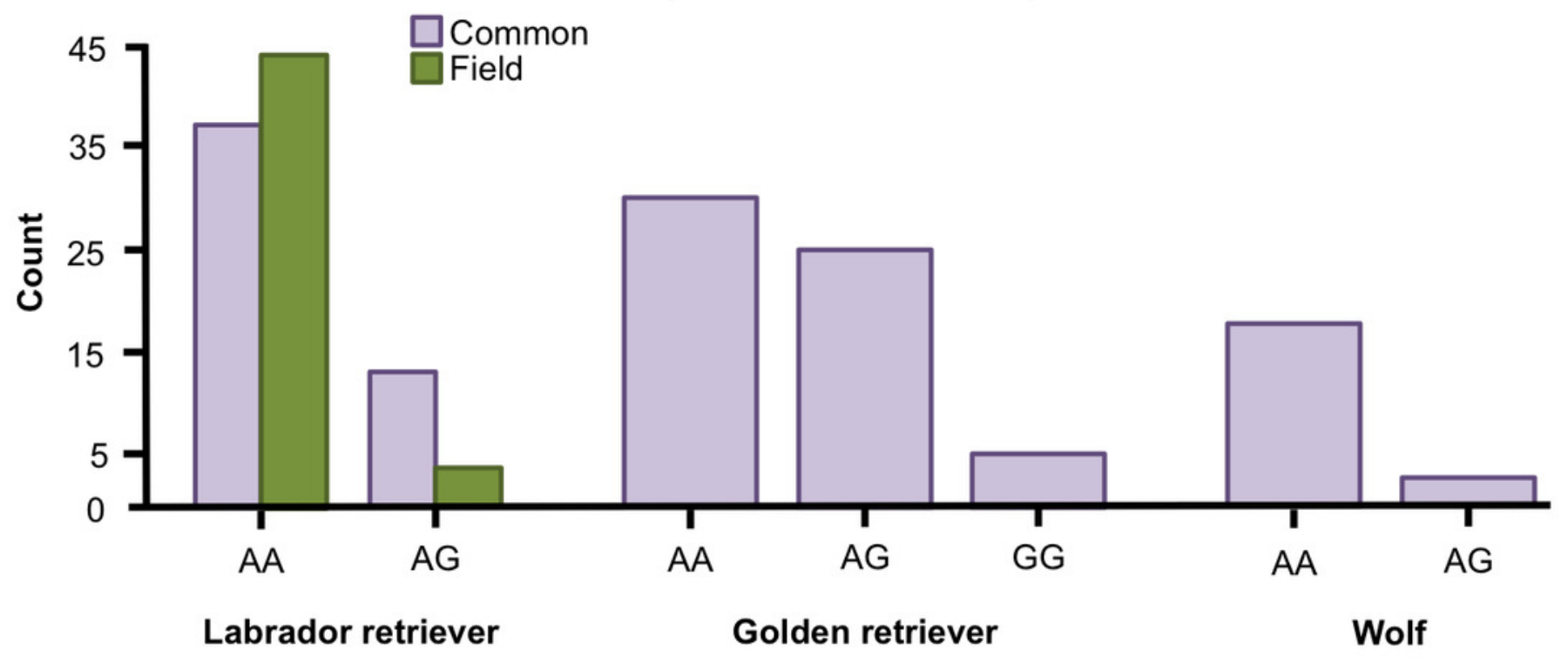


Figure 3

Associations between SNP1 and behaviours in golden retrievers

Associations between BICF2G630798942 (SNP1) and the frequency/duration for behaviours scored in the unsolvable problem task in golden retrievers. There was a significant difference between the genotypes in $(A)$ the frequency of physical contact with the experimenter, and (B) and (C) the frequency and duration of physical contact with the owner. Graphs show mean frequency/duration for each of the genotypes. Error bars show $\pm 1 \mathrm{SE} . * \mathrm{P}<0,05$

A)

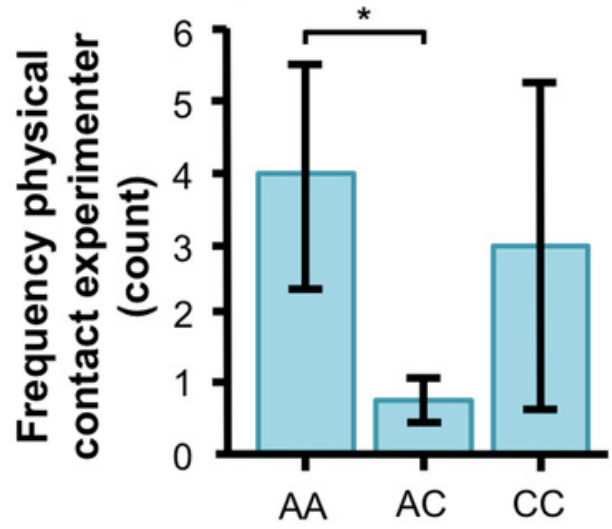

B)

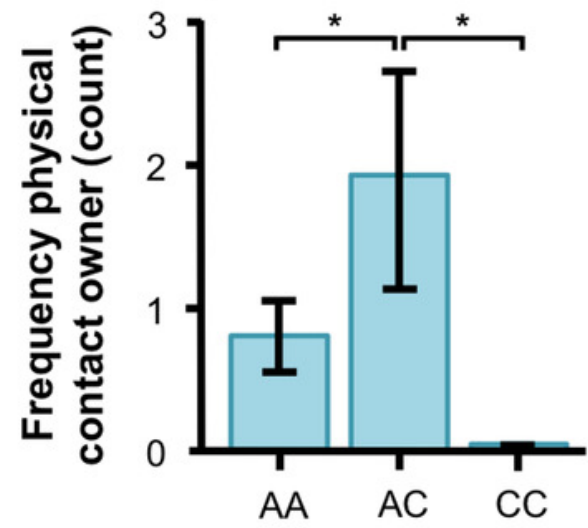

SNP1
C)

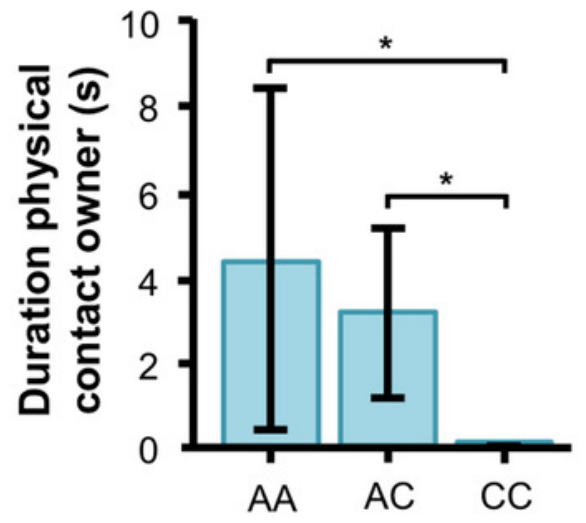


Figure 4

Associations between SNP1 and behaviours in Labrador retrievers

For the duration of owner gaze there was an interaction between genotype and type. The SNP BICF2G630798942 (SNP1) was associated with owner gaze in the field type but not in the common type. Graph shows mean duration for each of the genotypes. Error bars show \pm 1 SE. $* P<0,05$ 


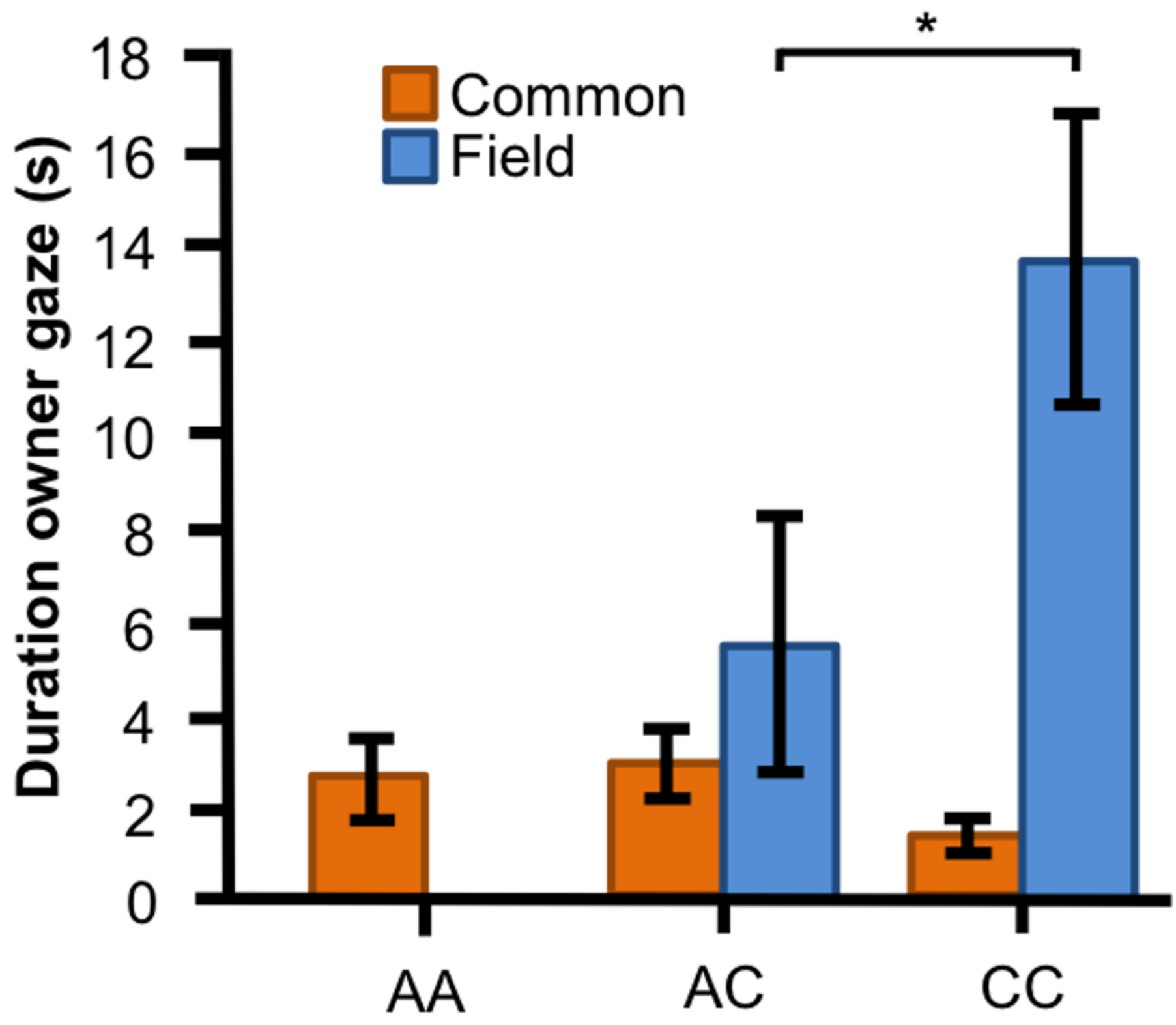

SNP1 
Figure 5

Associations between SNP2 and behaviours in golden retrievers

Associations between the genotype on the SNP BICF2S23712114 (SNP2) and the frequency/duration for behaviours scored in the unsolvable problem task in golden retrievers. There was a significant difference between the genotypes in $(A)$ the duration in the experimenter zone, (B) the frequency of gazing at the experimenter, (C) and (D) the frequency and duration of gazing at the owner, and $(E)$ the duration of physical contact with the owner. Graphs show mean frequency/duration for each of the genotypes. Error bars show \pm 1 SE. $* P<0,05$

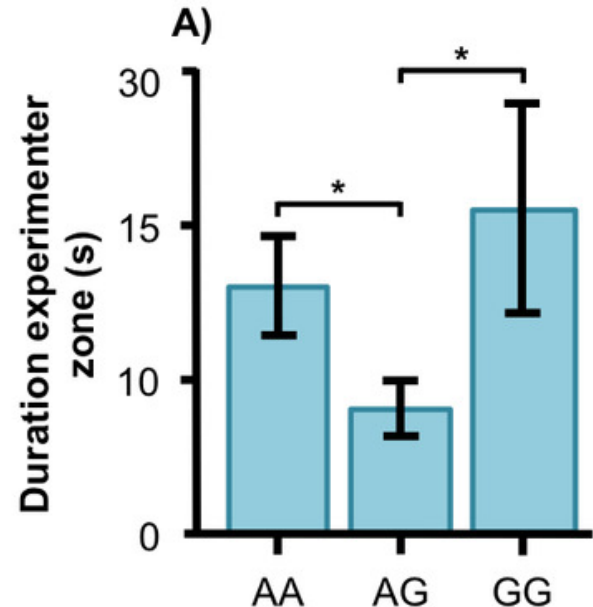

AA AG GG
B)

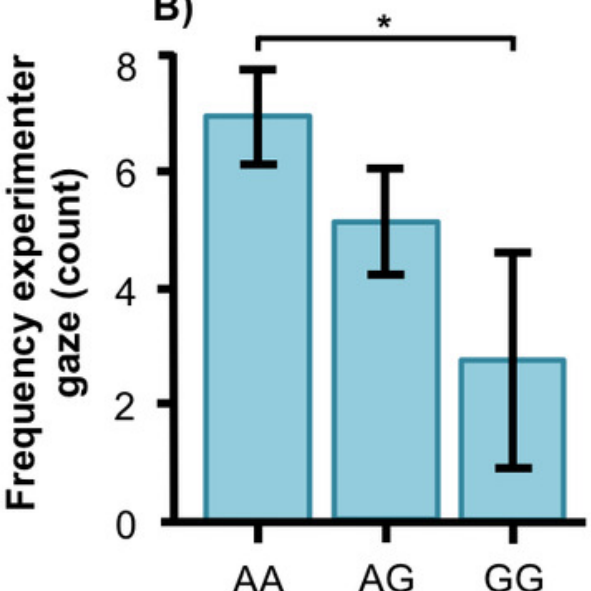

AA AG GG

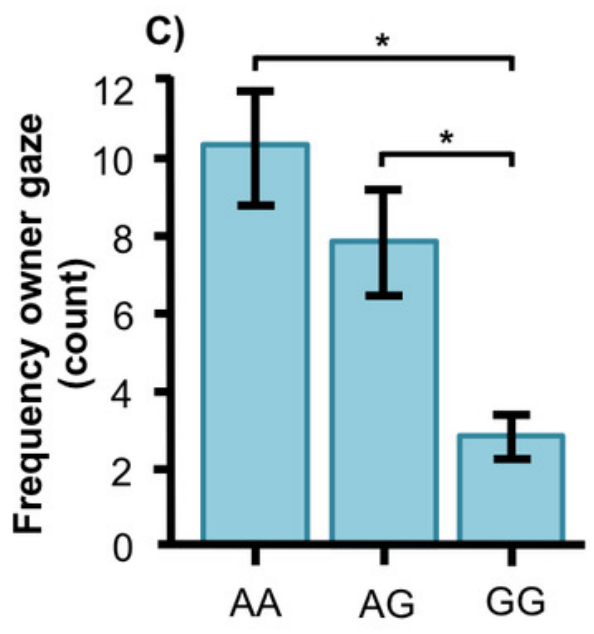

E)
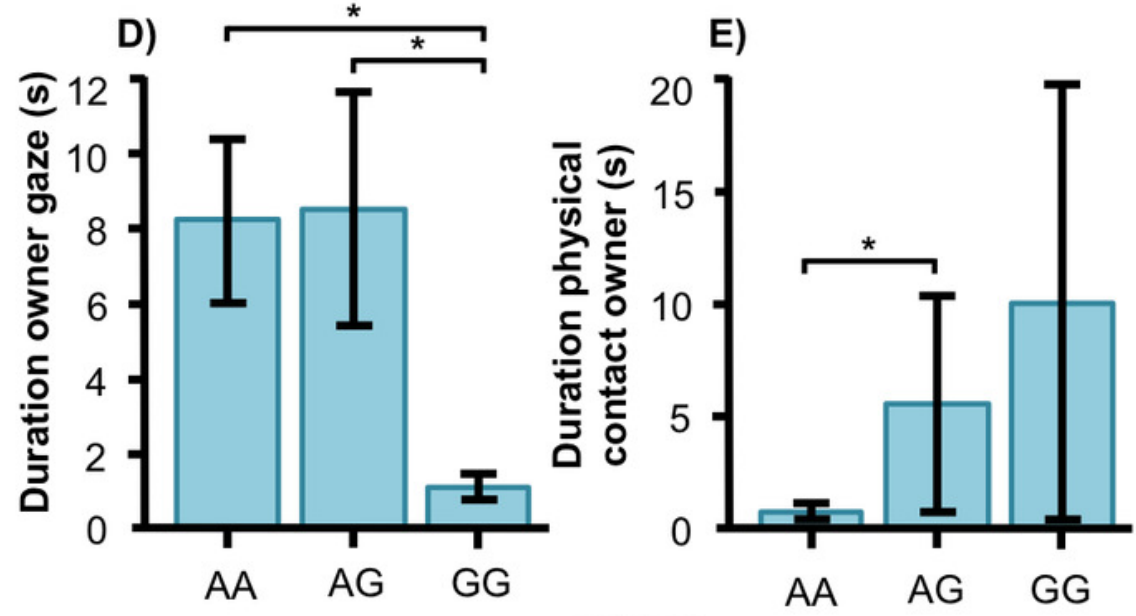

SNP2 


\section{Figure 6}

Associations between SNP2 and behaviours in Labrador retrievers

Associations between the genotype on the SNP BICF2S23712114 (SNP2) and the frequency/duration for behaviours scored in the unsolvable problem task in Labrador retrievers. There was a significant difference between the genotypes in $(A)$ the duration in the experimenter zone, (B) the frequency of gazing at the experimenter, $(C)$ and $(D)$ the frequency and duration of gazing at the owner, and $(E)$ the duration of physical contact with the owner. Graphs show mean frequency/duration for each of the genotypes. Error bars show \pm 1 SE. $* P<0,05$ 
A)

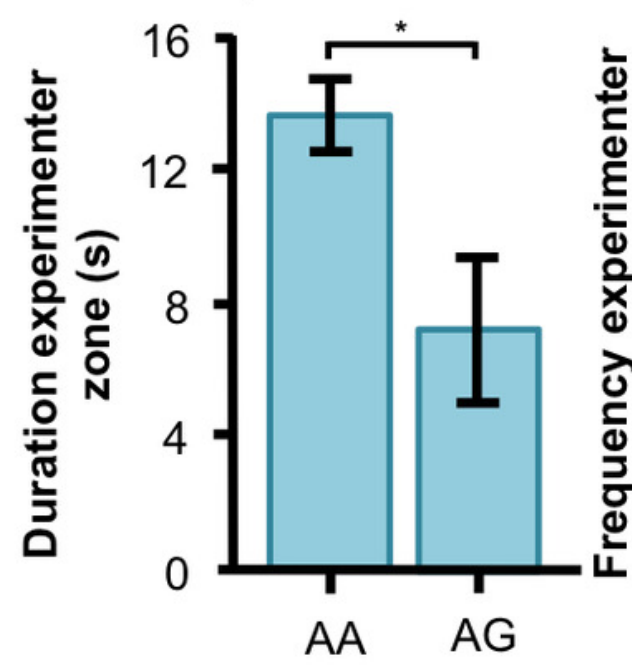

D)

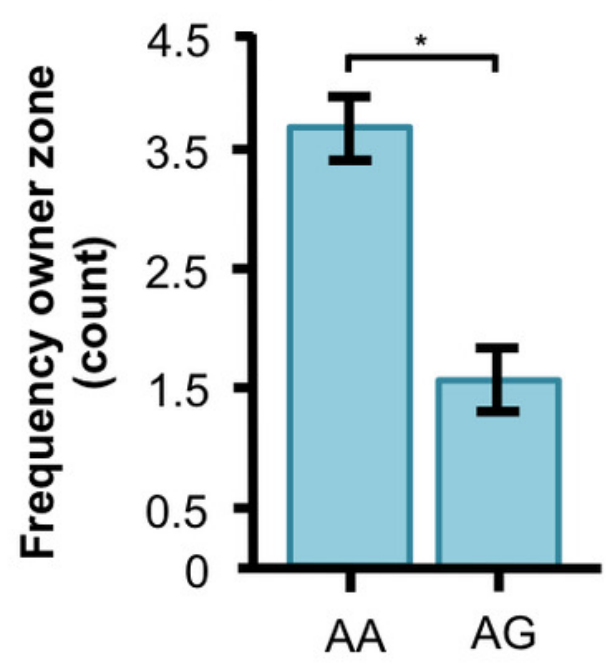

C)

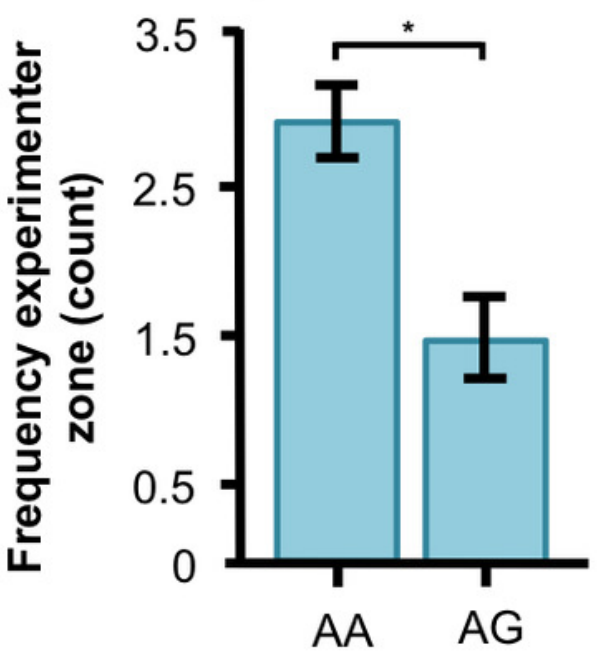

E)

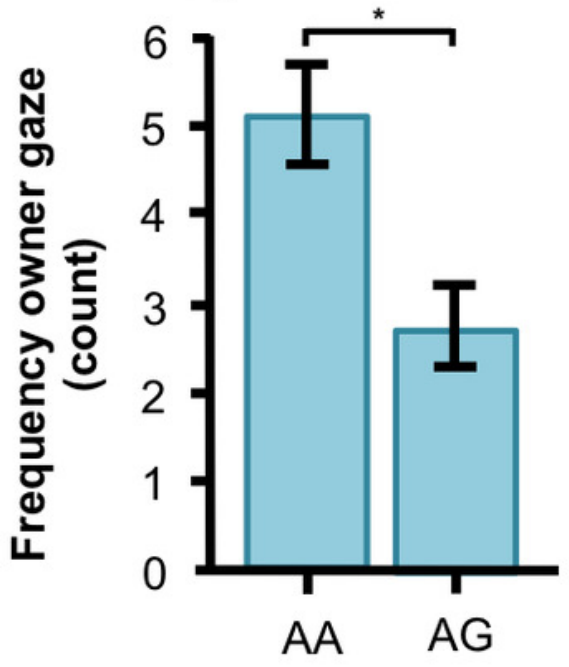

SNP2
B)

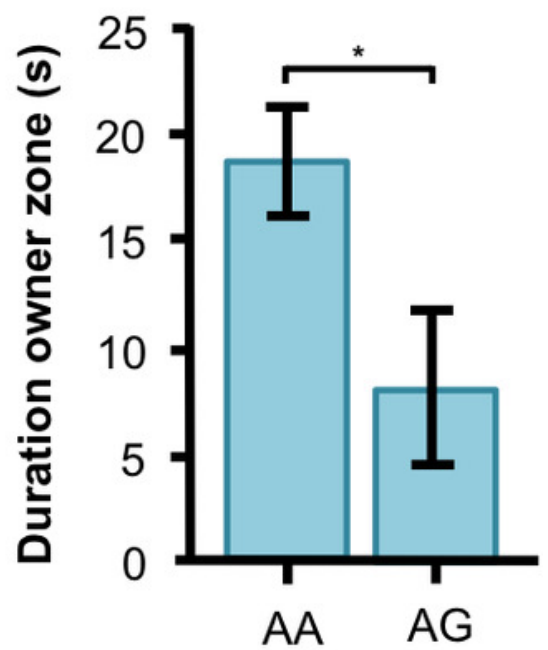

F)

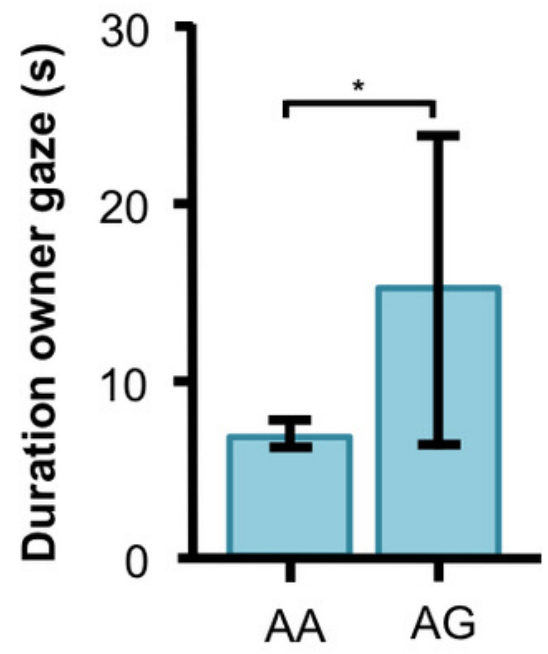


Figure 7

Interactions between SNP2 and type in Labrador retrievers

For $(A)$ the duration of experimenter gaze, and $(B)$ the frequency of owner gaze, there was an interaction between the SNP BICF2S23712114 (SNP2) and type (common or field) in Labrador retrievers. While genotype was associated with both behaviours in the field type Labradors, they were not associated with the behaviours in the common type. Graphs show mean frequency/duration for each of the genotypes. Error bars show $\pm 1 \mathrm{SE}$. $* \mathrm{P}<0,05$

A)

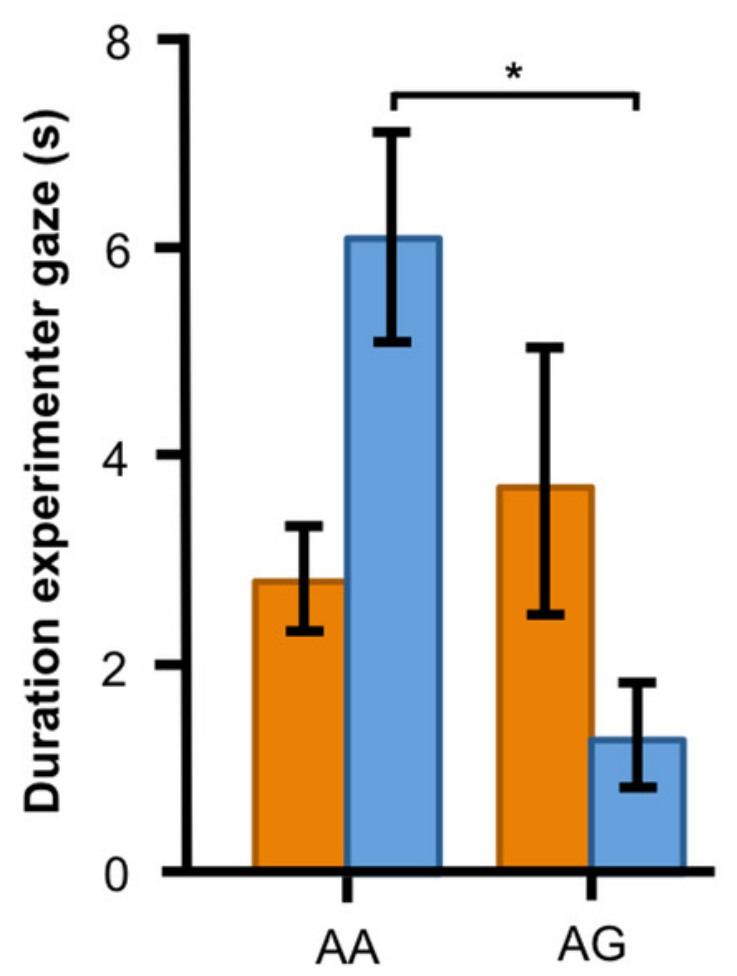

B)

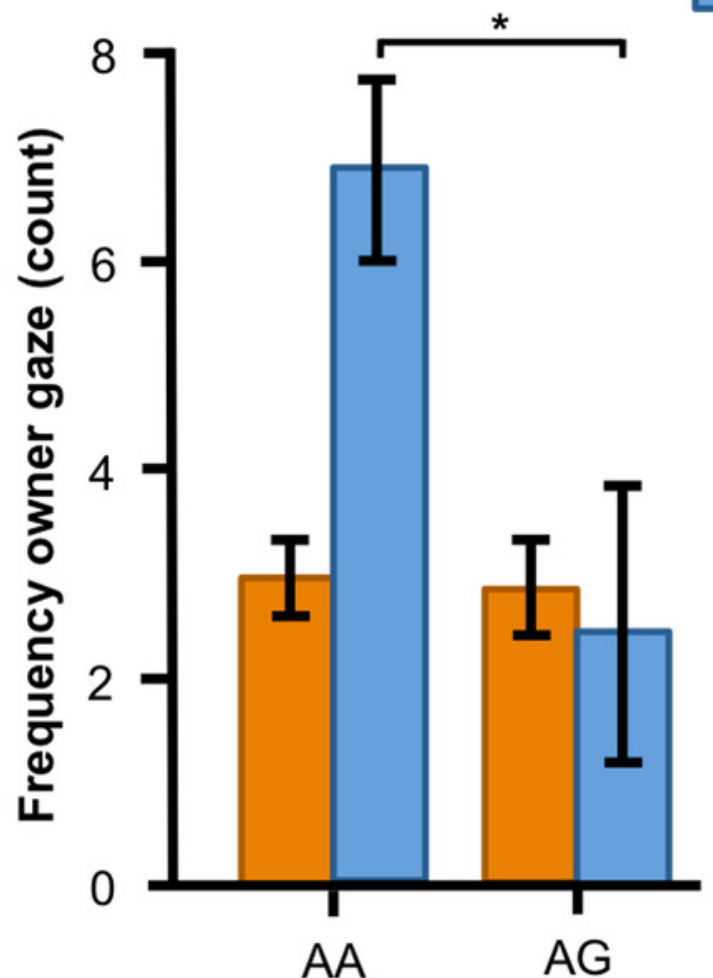

Common

Field 